\title{
Approaches for synthesis and chemical modification of non-condensed heterocyclic systems based on 1,3,4-oxadiazole ring and their biological activity: A review
}

\author{
Maryan Lelyukh ${ }^{1 *}$, Marta Martynets ${ }^{2}$, Myroslava Kalytovska $^{3}$, Iryna Drapak ${ }^{4}$, Stefan Harkov ${ }^{5}$, Taras Chaban ${ }^{4}$, Ihor Chaban ${ }^{1}$, \\ Vasyl Matiychuk ${ }^{6}$ \\ ${ }^{1}$ Department of Pharmaceutical, Organic and Bioorganic Chemistry, Danylo Halytsky Lviv National Medical University, Lviv, Ukraine. \\ ${ }^{2}$ Department of Oral Surgery and Prosthetic Dentistry FPGE, Danylo Halytsky Lviv National Medical University, Lviv, Ukraine. \\ ${ }^{3}$ Department of Pharmacy and Biology, Stepan Gzhytskyi National University of Veterinary Medicine and Biotechnologies Lviv, Lviv, Ukraine. \\ ${ }^{4}$ Department of General, Bioinorganic, Physical and Colloidal Chemistry, Danylo Halytsky Lviv National Medical University, Lviv, Ukraine. \\ ${ }^{5}$ Department of Pharmacy, Medical College of Burgas University "Prof. Dr. Asen Zlatarov", Burgas, Bulgaria. \\ ${ }^{6}$ Department of Organic Chemistry, Ivan Franko National University of Lviv, Lviv, Ukraine.
}

\section{ARTICLE INFO \\ Received on: 08/08/2019 \\ Accepted on: 26/06/2020 \\ Available online: 05/10/2020}

\section{Key words:}

Synthesis, 1,3,4-oxadiazoles, chemical modification,

biological activity.

\begin{abstract}
1,3,4-Oxadiazole scaffold is one of the most important heterocyclic fragments, which is considered as a perspective building block for drug discovery. Substituted 1,3,4-oxadiazoles had been reported to display a diverse range of pharmacological activities including anticancer, anti-inflammatory, antitubercular, antibacterial, antiviral, antifungal, insecticidal, antioxidant, and analgesic activities. Moreover, the 1,3,4-oxadiazole core is a structural component of approved antiretroviral (Raltegravir), anticancer (Zibotentan), and antihypertensive (Tiodazosin and Nesapidil) drugs. In the present review, we summarized the literature data about the main approaches for obtaining possible directions of structural modification and pharmacological activity of noncondensed heterocyclic systems based on the 1,3,4-oxadiazole ring as promising objects for modern bioorganic and medicinal chemistry.
\end{abstract}

\section{INTRODUCTION}

Molecular design and synthesis of new biologically active small molecules based on heterocyclic scaffolds are the important trends in modern organic and medicinal chemistry. The promising objects for drug discovery belong to quite a few oxygen- and nitrogen-containing five-membered heterocycles. In particular, 1,3,4-oxadiazole core is a known pharmacophore fragment, which possesses a wide range of opportunities for chemical modification and versatile pharmacological potential including anticancer (Ahsan et al., 2018; Rashid et al., 2012), antimicrobial (Bakht et al., 2010; Dhumal et al., 2016), antifungal (Naveena et al., 2010; Nimbalkar et al., 2016), antiviral (Albratty et al., 2019; Gan et al.,

\footnotetext{
"Corresponding Author

Maryan Lelyukh, Department of Pharmaceutical Chemistry FPGE, Danylo Halytsky Lviv National Medical University, Lviv, Ukraine. E-mail:lelyukh.m@gmail.com
}

2016), antitubercular (Desai et al., 2018), anesthetic (Rajak et al., 2008), and anti-inflammatory and analgesic (Akhter et al., 2009; Rasheed et al., 2018) action.

Moreover, among 1,3,4-oxadiazole derivatives, the promising inhibitors of histone deacetylase (HDAC) I (Rajak et al., 2011), telomerase II (Zhang et al., 2012a), and focal adhesion kinase III (Zhang et al., 2013) have been identified as potential antitumor agents (Figure 1). Furthermore, oxadiazoles have been reported as the inductors of mitochondrial-mediated apoptosis (Kamal et al., 2010), inhibitors of $\alpha$-glucosidase (Kashtoh et al., 2014), cathepsin K (Palmer et al., 2006), glycogen synthase

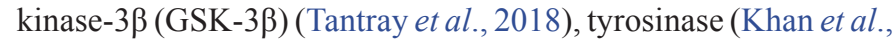
2005), nucleotide pyrophosphatases/phosphodiesterases-1 NPP1 (Khan et al., 2009), urease (Abbasi et al., 2018), COX-2/5-LOX biosystem (Boschelli et al., 1993), and so forth. 1,3,4-oxadiazole derivatives belong to an antiretroviral drug-Raltegravirbeing the first representative of the new class of HIV-1 integrase inhibitor (Cahn and Sued, 2007; Grinsztejn et al., 2007). 
It is important to note that a combination of the 1,3,4-oxadiazole core with various heterocyclic fragments was accompanied by the emergence of a synergistic effect in many cases (Ahsan et al., 2011; Kotaiah et al., 2012; Padmavathi et al., 2011; Puthiyapurayil et al., 2012). Moreover, 1,3,4-oxadiazole cycle is a bioisostere for carboxylic, amide, and ester groups, which mostly contribute to the enhancement of the pharmacological activity by participating in the hydrogen bonding interactions with the receptors (Guimarães et al., 2005).

\section{Synthetic approaches for the construction of 1,3,4-oxadiazole cycle and possible directions of chemical modification of its derivatives}

A known method for obtaining 2-mercapto-1,3,4-oxadiazole derivatives is based on the interaction of carboxylic acid hydrazides with carbon disulfide by heating in the alcoholic solution of alkali. Hence, the synthesis of furyl substituted 1,3,4-oxadiazole-2-thiol 1 was carried out starting from furan-2-carboxylic acid hydrazide in the abovementioned conditions (Koparir et al., 2010):

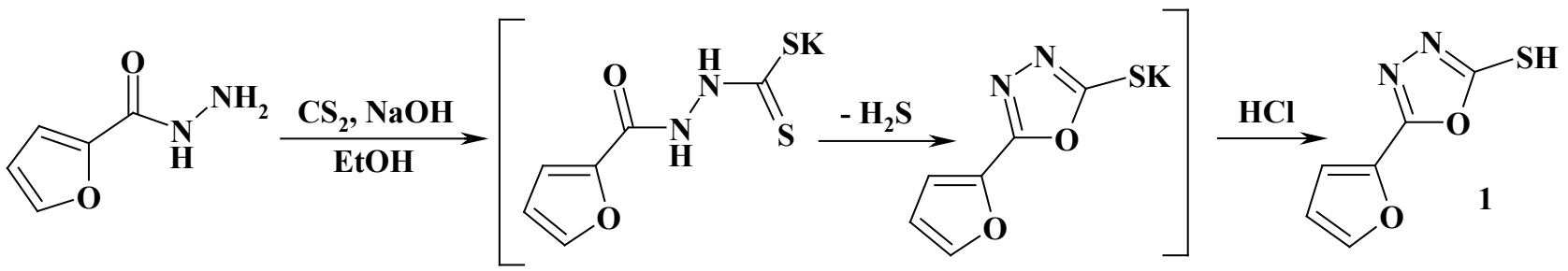

The presence of thiol-thione tautomerism caused a further chemical modification of compound $\mathbf{1}$ via $S$-alkylation reaction with methyl iodide and Mannich reaction with formaldehyde and aromatic or cyclic amines with the formation of the corresponding 2-methylmercapto-1,3,4-oxadiazoles 2 and 3H-1,3,4-diazoline-2-thiones 3 (Koparir et al., 2010).<smiles>[R]Cn1nc(-c2ccco2)oc1=S</smiles>

Following the ring-closure procedure, on treating hexanedioic acid dihydrazide with chloroacetic acid in refluxing phosphorus oxychloride, the corresponding 1,4-bis(1,3,4-oxadiazole-2-yl)butane 4 was synthesized. The target quaternary ammonium salts $\mathbf{5}$ were obtained by refluxing compound $\mathbf{4}$ in acetone medium with the appropriate tertiary amine, 2-(dimethylamino)ethyl methacrylate, or 2-(diethylamino)ethyl methacrylate, respectively (Rohand et al., 2019).

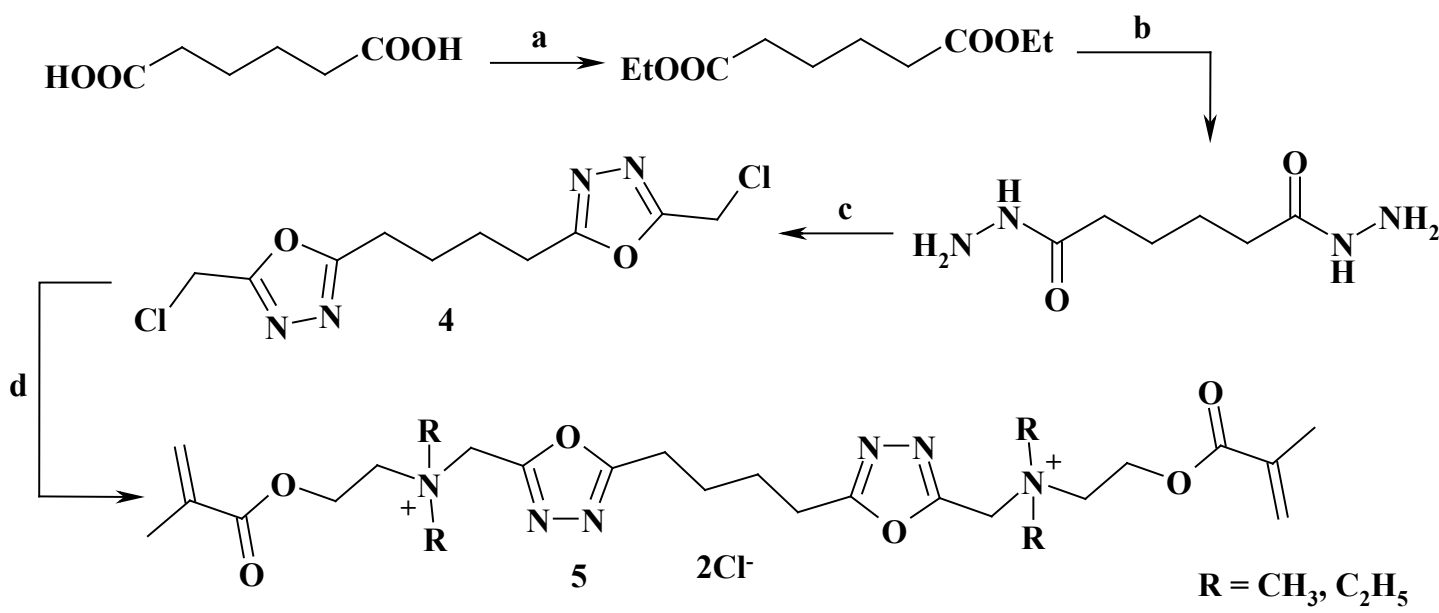

(a) $\mathrm{C}_{2} \mathrm{H}_{5} \mathrm{OH}, \mathrm{H}_{2} \mathrm{SO}_{4}$ conc., reflux, 12h; (b) $\mathrm{NH}_{2} \mathrm{NH}_{2} \cdot \mathrm{H}_{2} \mathrm{O}, \mathrm{C}_{2} \mathrm{H}_{5} \mathrm{OH}$, reflux, 8h;

(c) $\mathrm{POCl}_{3}, \mathrm{CICH}_{2} \mathrm{COOH}$, reflux, 8h; (d) DMAEMA/DEAEMA, acetone, reflux, $24 \mathrm{~h}$.

The synthesis of 2-mercapto-1,3,4-oxadiazoles 6 containing pyrazole moiety was proposed by Chen et al. (2000) starting from pyrazole-5-carboxylic acid hydrazides in the similar transformations. An interaction of compound $\mathbf{6}$ with alkyl iodides in the presence of tetrabutylammonium bromide resulted in the formation of the corresponding $S$-alkylated derivatives 7. 


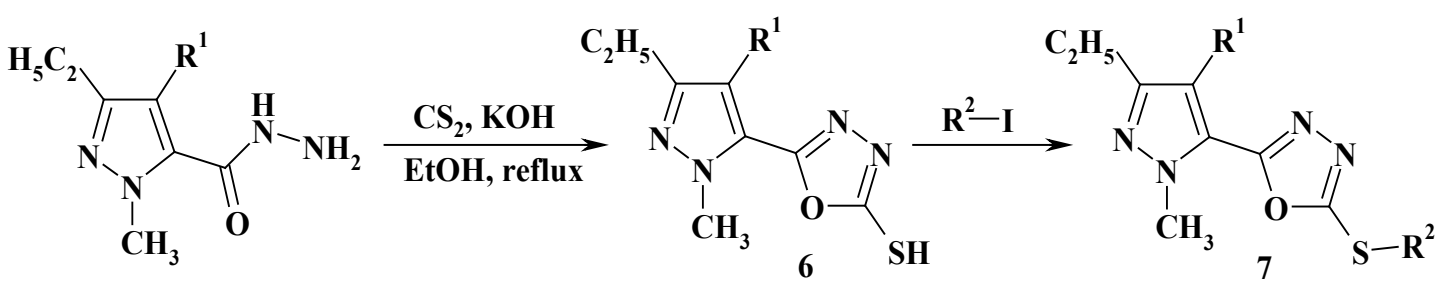

The cyclization of $N$-acylated aliphatic amino acid hydrazides with carbon disulfide in an ethanolic solution of potassium hydroxide resulted in 2,3-dihydro-1,3,4-oxadiazole-2-thiones $\mathbf{8}$, which on reaction with hydrazine hydrate was subsequently modified with the formation of corresponding 1,2,4-triazole-5-thiones $\mathbf{9}$. The existence of two tautomeric forms for compounds 8 and $\mathbf{9}$ (thione in solid state and thiol in solution) was confirmed by the presence of an absorption band at 1,240-1,142 $\mathrm{cm}^{-1}$ on Infrared (IR) spectra, which corresponds to the $\mathrm{C}=\mathrm{S}$ group of thione form, and the characteristic signal at $14-15 \mathrm{ppm}$ on ${ }^{1} \mathrm{H}$ Nuclear magnetic resonance (NMR) spectra due to SH-group (Feng et al., 2012).

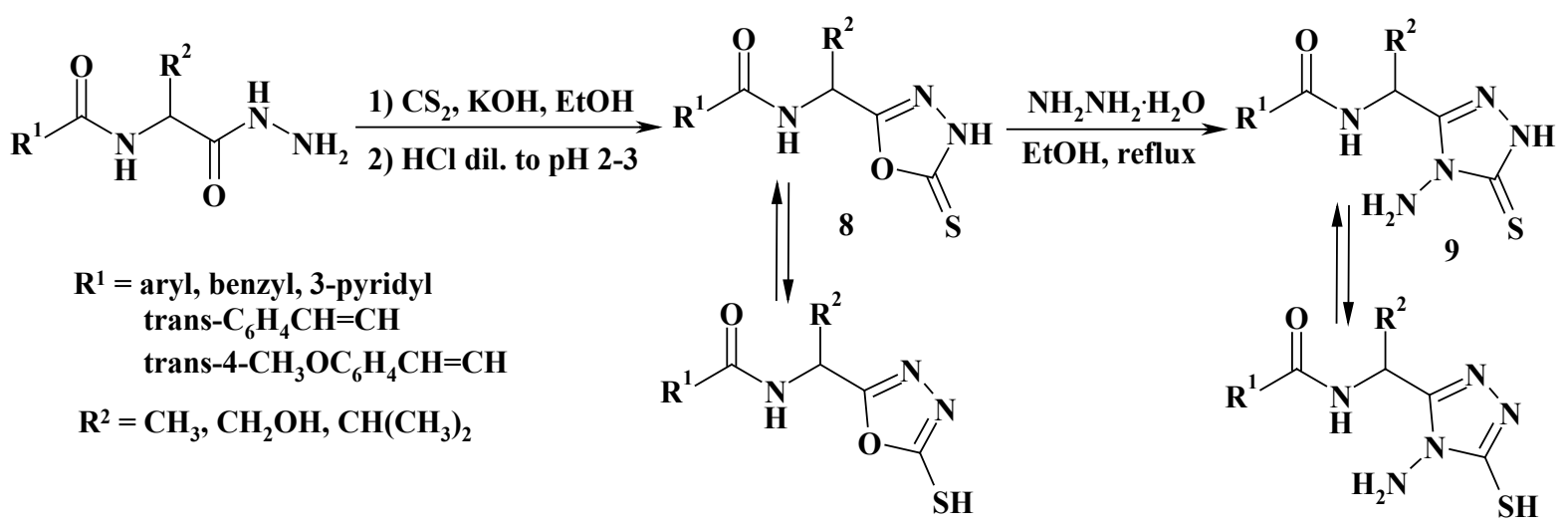

The synthesis of 3-arylamino(piperazinyl)methylene-substituted 1,3,4-oxadiazole-2-thiones 11-13 was carried out by the interaction of 5-(thiophene-2-yl)-1,3,4-oxadiazole-2-thiol $\mathbf{1 0}$ as a starting reagent with primary aromatic amines, $N$-substituted piperazine, or aniline derivatives according to the Mannich reaction procedure (Al-Omar, 2010):

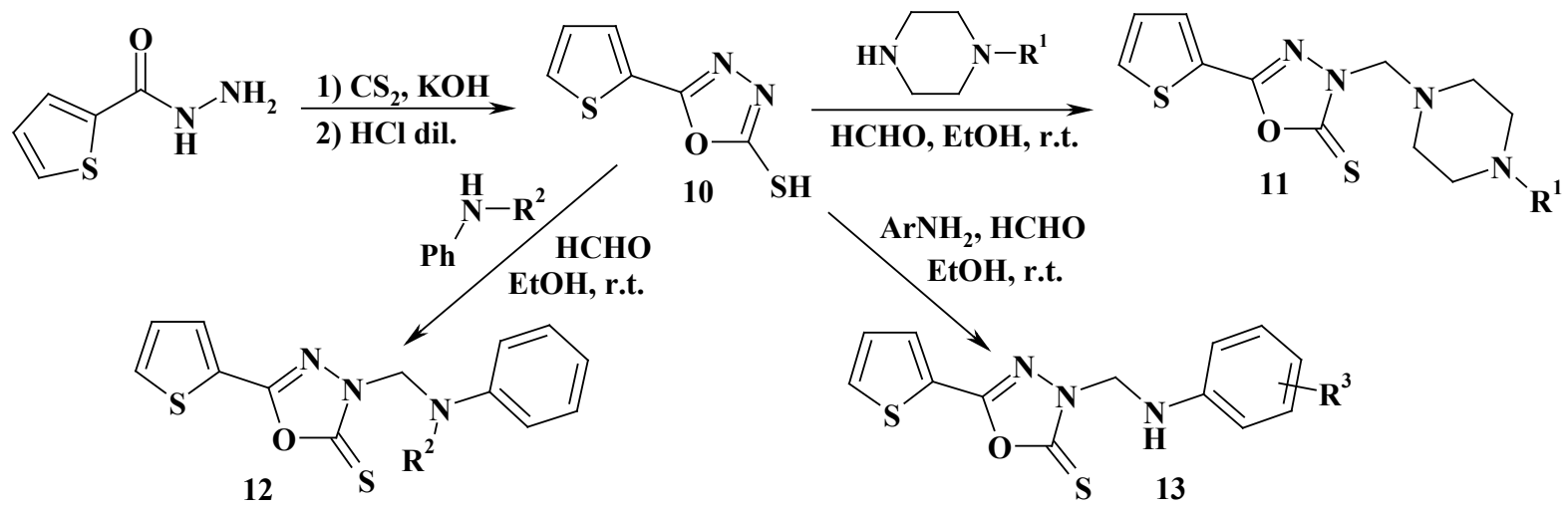

Based on (E)- $\alpha$-(methoxyimino)-[(2'-bromomethyl)phenyl]acetic acid methyl ester $\mathbf{1 4}$ as an alkylating agent, the synthesis of 5-aryl substituted 2-mercapto-1,3,4-oxadiazoles 15 was carried out (Li et al., 2006).<smiles>CO/N=C(\C(=O)OC)c1ccccc1CBr</smiles><smiles>[R]c1ccc(C(=O)NNNC(=O)COc2ccccc2)cc1</smiles>

(a) $\mathrm{HON}=\mathrm{CH}-\mathrm{COOMe}, \mathrm{CuSO}_{4}-\mathrm{Na}_{2} \mathrm{SO}_{3}, \mathrm{pH}$ 6-7; (b) $\mathrm{NaH}, \mathrm{Me}_{2} \mathrm{SO}_{4}$; 15 (c) NBS, $\mathrm{CCl}_{4}$, reflux; (d) $\mathrm{CS}_{2}$, $\mathrm{KOH}$, reflux 8h; (e) $\mathrm{CH}_{3} \mathrm{ONa} / \mathrm{DMF}$, overnight 
In similar transformations, the hydrazides of 4-substituted salicylic acids were used for the synthesis of corresponding 1,3,4-oxadiazole-2-thiols 16, which on reaction with benzyl bromides afforded the group of $S$-alkylated derivatives $\mathbf{1 7}$ (Zhang et al., 2012 b):

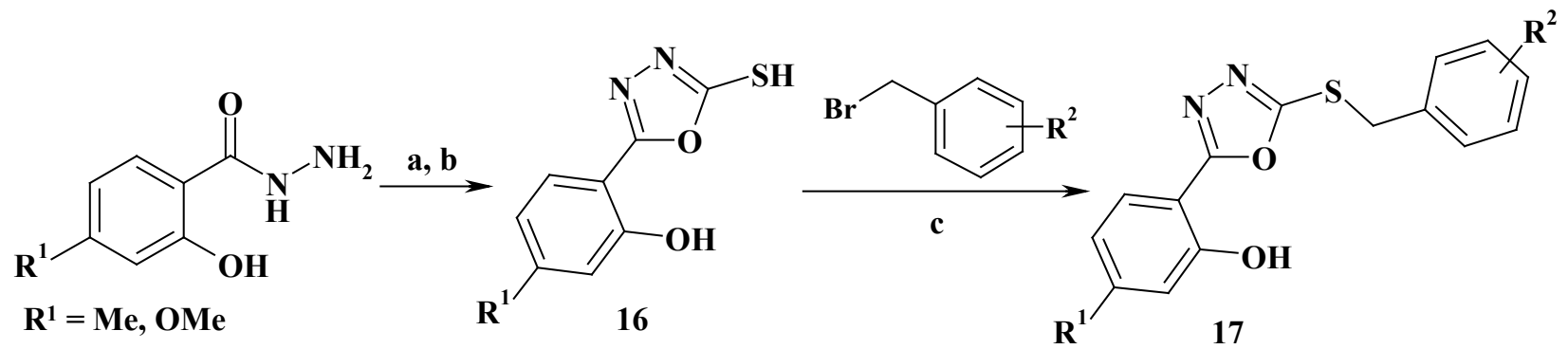

(a) $\mathrm{CS}_{2} / \mathrm{KOH}, 95 \%$ ethanol, reflux, 24 h; (b) HCl, pH 5-6; (c) NaOH, acetonitrile, reflux, 8-24 h.

The synthesis of thiazole-substituted 1,3,4-oxadiazole-2-thiol 19 was performed by the cyclization reaction of 2-benzoylamino1,3-thiazol-4-acetic acid hydrazide 18 with carbon disulfide in an ethanolic solution of alkali. The reaction of compound 19 with 3-bromo$\mathrm{N}$-(un/substituted-phenyl)propanamides in dimethylformamide medium using $\mathrm{LiH}$ as a basic catalyst gave the target thiazole-1,3,4oxadiazole-based diamides 20 (Abbasi et al., 2018).<smiles>CCOC(=O)Cc1csc(NC(=O)c2cccc(C)c2)n1</smiles><smiles>CC(C)c1cccc(C(=O)Nc2nc(CC(=O)NN)cs2)c1</smiles>

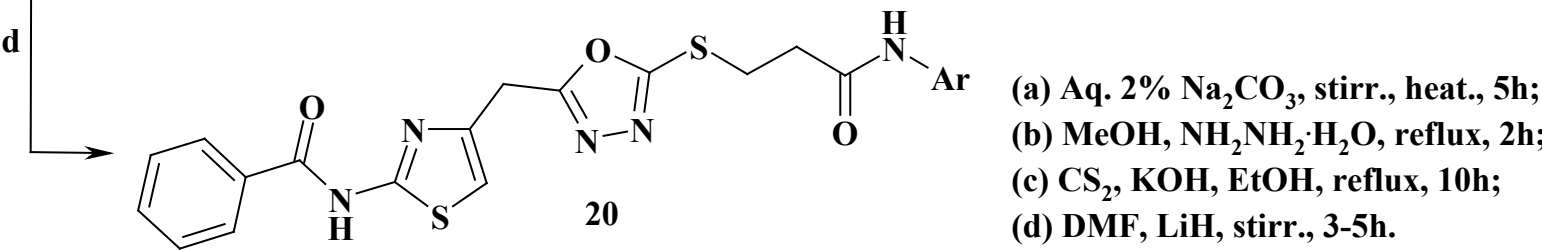

The sequential transformations of 3-fluoro-4-methoxyacetophenone with diethyl oxalate and hydroxylamine hydrochloride, respectively, gave ethyl isoxazole-3-carboxylate $\mathbf{2 1}$ which on hydrazinolysis procedure afforded the respective acid hydrazide $\mathbf{2 2}$. The further cyclization of $\mathbf{2 2}$ with carboxylic acids in phosphorus oxochloride medium resulted in a series of isoxazole-substituted 1,3,4-oxadiazoles 23 with 3-fluoro-4-methoxyphenyl moiety (Shingare et al., 2018).

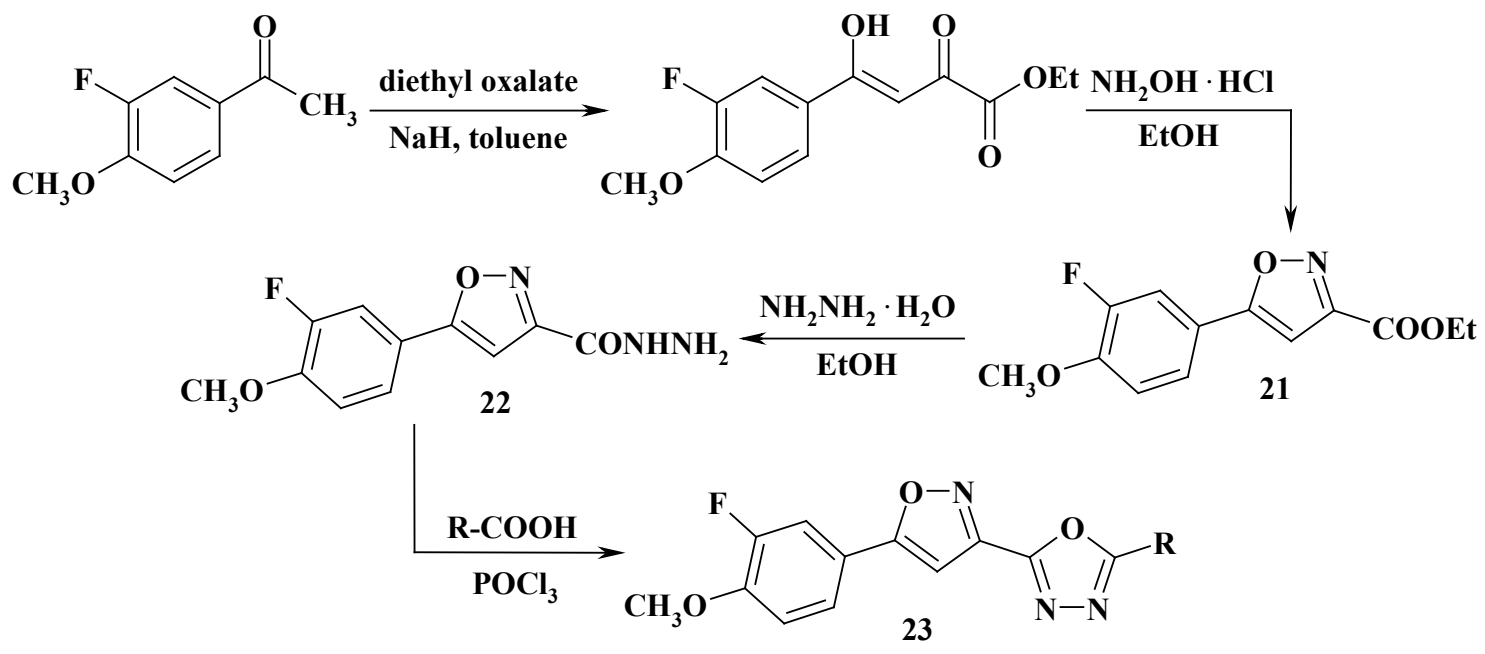


Jakubkiene et al. (2003) proposed a method for obtaining 1,3,4-oxadiazole-2-thiols 24, based on cyclization of carboxylic acid hydrazides with potassium $O$-ethylxanthate in ethanol medium. By implementing this approach, a group of 3-morpholinomethylenesubstituted 1,3,4-oxadiazole-2(3H)-thiones $\mathbf{2 5}$ with pyrimidine fragment was synthesized.<smiles>[R]c1nc(C)cc(OCC(=O)NNN)n1</smiles>

Following the hydrazinolysis of pyrazolyl-furan-2-one derivatives, the appropriate $\alpha$-pyrazolyl-4-ylmethylidene- $\beta$-aroylpropionic acid hydrazides 26 were obtained and utilized for the synthesis of noncondensed 1,3,4-oxadiazole-substituted pyrazoles 27 (Hashem et al., 2007).<smiles>CC(C)CC(=O)CC(=Cc1cn(-c2ccccc2)nc1-c1ccccc1)C(=O)NNC(=O)[Al]</smiles>

(a) $\mathrm{NH}_{2} \mathrm{NH}_{2}$, EtOH, r.t., stirring; (b) $\mathrm{CS}_{2}$, NaOH, EtOH, reflux, 2h; (c) $\mathrm{HCl}$ dil.

A group of 2-amino-1,3,4-oxadiazoles 28 and 1,3,4-oxadiazole-2-thiols 29-30 with (benzyloxy)phenyl fragment were synthesized and evaluated as promising anticonvulsant agents (Zarghi et al., 2005).

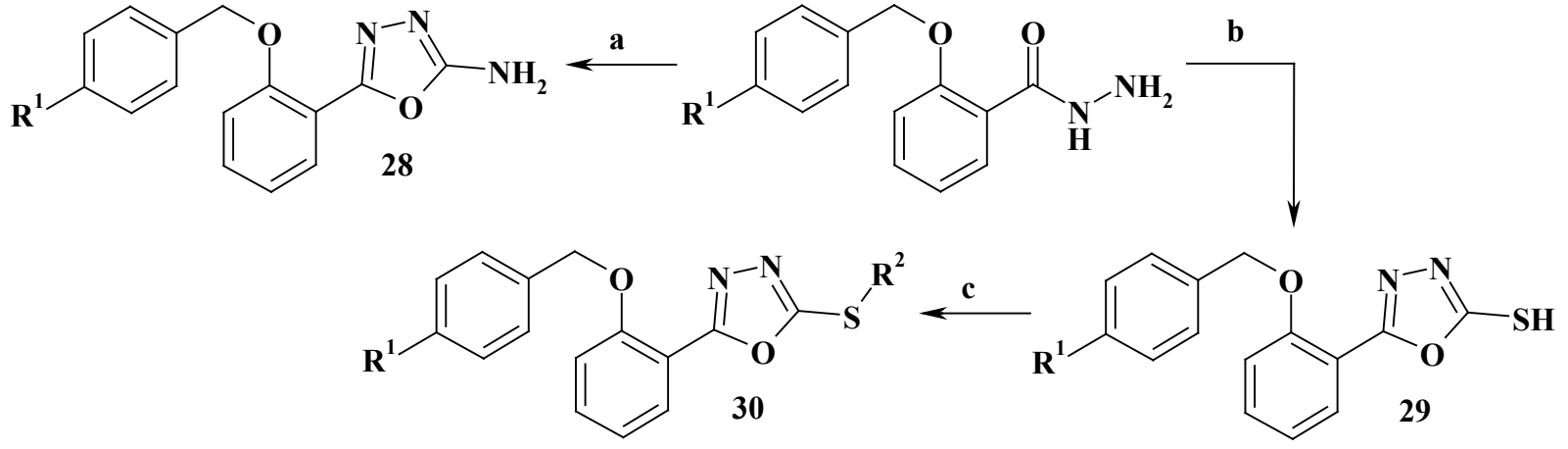

(a) BrCN, $\mathrm{NaHCO}_{3}$, MeOH, rt, 3h; (b) $\mathrm{CS}_{2}$, KOH, EtOH, reflux, 6h; (c) RI, NaOH, EtOH, sonication, 20 min.

According to the concept of hybrid-pharmacophore approach, a series of novel 5-aryl-1,3,4-oxadiazol-2(3H)-ones with 1,2,3-triazole 33 and isoxazole 34 fragments as potential anticancer agents were synthesized by Madhavilatha et al. (2018). Thus, the starting 1,3,4-oxadiazole-2(3H)-ones 31 were modified by reacting with propargyl bromide in the presence of NaH into the corresponding $\mathrm{N}$-propargylated derivatives 32 which reacted with various azides or aldoximes giving the target 1,3,4-oxadiazole containing 1,2,3-triazole $\mathbf{3 3}$ and isoxazole $\mathbf{3 4}$ derivatives. 


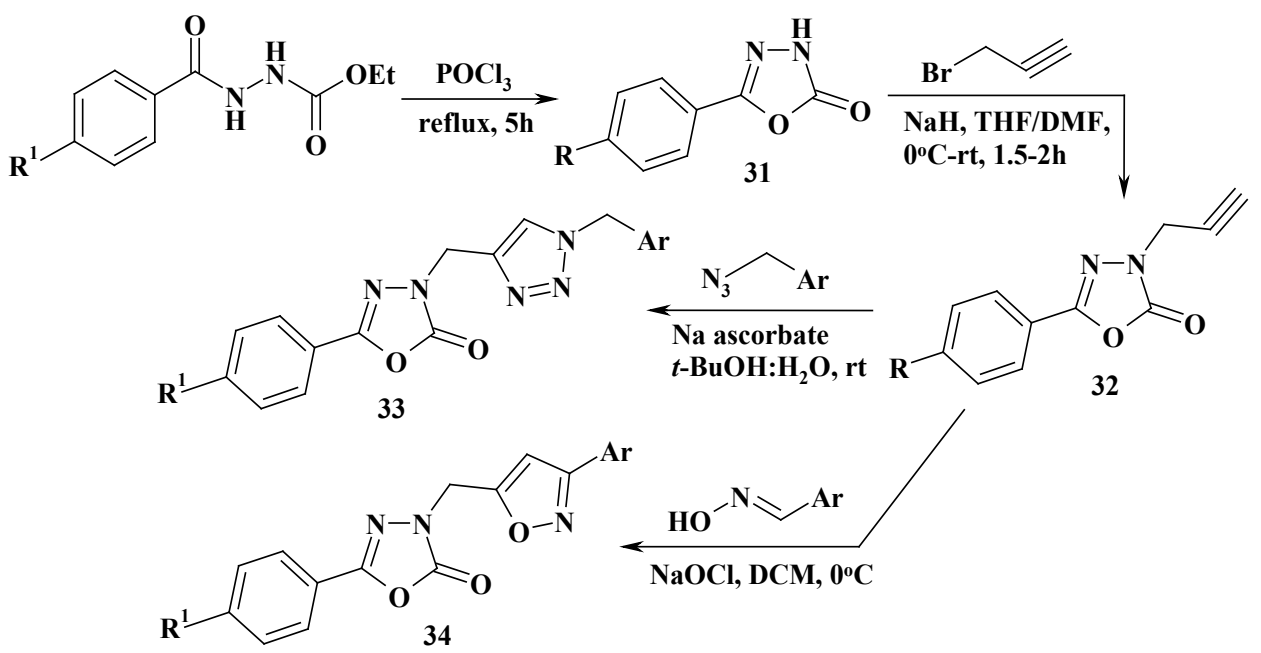

The cyclodesulfurization reaction of $N^{4}$-benzoyl- $N^{I}$-cyanoacetylthiosemicarbazide on boiling in ethanolic mercuric oxide solution provided 5-benzoylamino-2-cyanomethyl-1,3,4-oxadiazole 35 as a starting reagent for the synthesis of new compounds with a promising antitumor activity (Bondock et al., 2012). Furthermore, an interaction of compound $\mathbf{3 5}$ with aromatic aldehydes in ethanol medium resulted in the formation of a series of corresponding arylidene derivatives 36. As an extension of the synthetic study, a new 1,3,4-oxadiazole-based coumarin 37 and naphtho[1,2-b]oxazines 38-39 were obtained by reacting compound $\mathbf{3 8}$ with salicylaldehyde, 1(2)-nitroso-2(1)-naphthols in ethanol solution using piperidine as the catalyst.

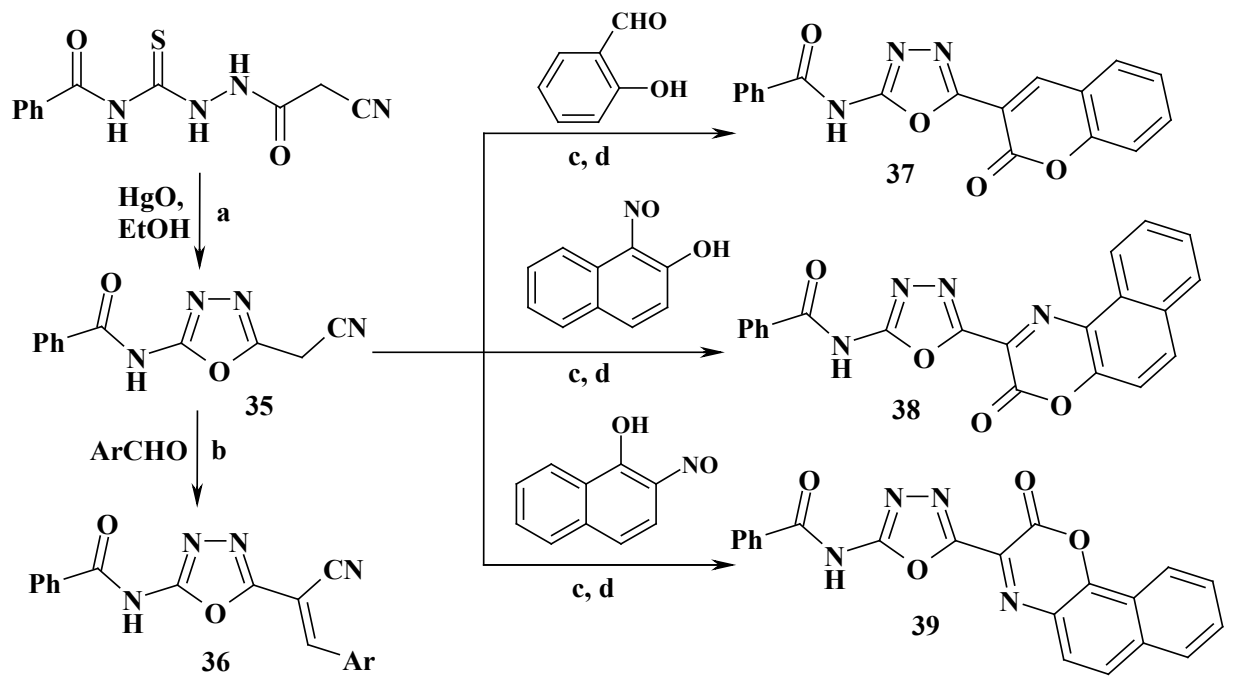

(a) EtOH, reflux, 4h; (b) triethylamine, EtOH, reflux, 6h; (c) piperidine, EtOH, reflux, 4h; (d) ice-water, HCl dil.

The interaction between indole-3-carbaldehyde and isoniazid yielded the isonicotinylhydrazide 40, which cyclized with acetic anhydride with the formation of 3-acetyl-2,3-dihydro-1,3,4-oxadiazole 41. The synthesis of target indole/pyridine containing 1,3,4-oxadiazoles 42 was carried out by heating of the compound 41 with appropriate arylcarbaldehydes in an ethanol solution of alkali (Desai et al., 2016).

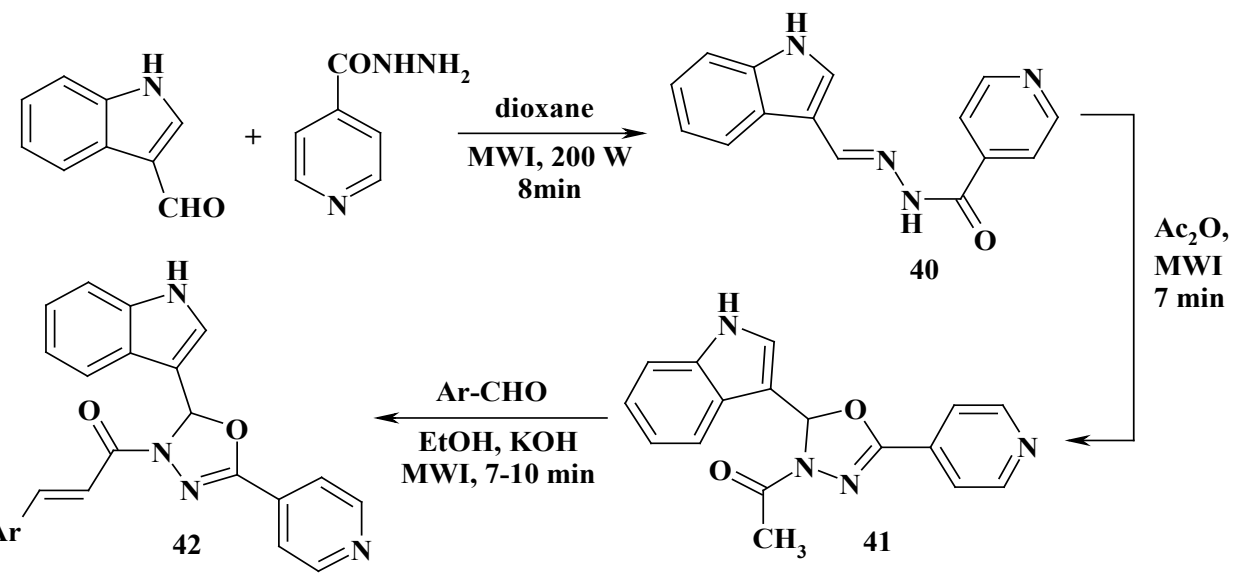


The $S$-alkylation reaction between 4-chloro-6-methylpyrimidine-2-thiol and 2-(chloromethyl)-5-phenyl-1,3,4-oxadiazole in tetrahydrofuran medium yielded the corresponding bis-heterocycle conjugate 43 . A series of new methylthio linked pyrimidinyl bis-1,3,4oxadiazoles 44 were prepared by the reaction of compound 43 with (5-phenyl-1,3,4-oxadiazol-2-yl)methanethiol in the presence of a catalytic amount of methanesulfonic acid under conventional and ultrasound irradiation conditions (Madhu Sekhar et al., 2018).

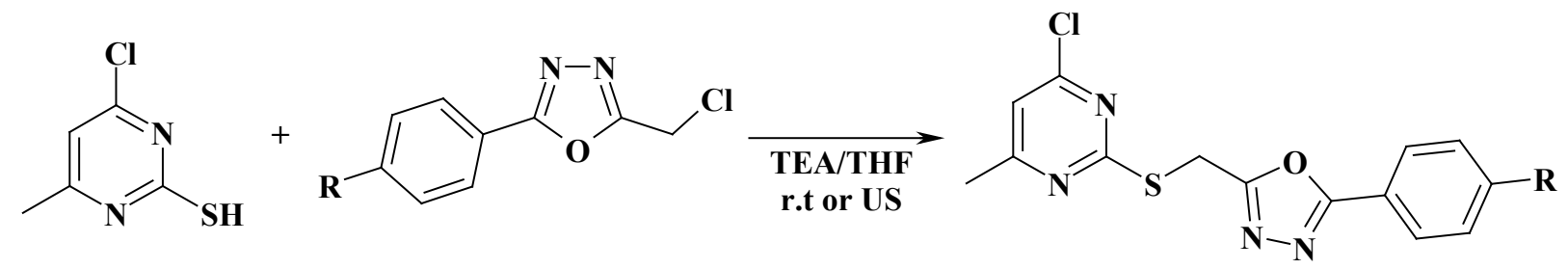

43<smiles>[R]c1ccc(-c2nnc(CSc3cc(C)nc(SCc4nnc(-c5ccc([R])cc5)o4)n3)o2)cc1</smiles>

Reacting diflunisal hydrazide with alkyl/aryl isothiocyanates in ethanol resulted in the formation of $N^{l}$-acylated 4-alkyl/ arylthiosemicarbazides $\mathbf{4 5}$. The cyclization of compounds $\mathbf{4 5}$ using iodine in alkaline medium afforded the corresponding 2-alkyl/ arylamino-5-(2',4'-difluoro-4-hydroxybiphenyl-5-yl)-1,3,4-oxadiazoles 46 (Küçükgüzel et al., 2007).<smiles>[R]Nc1nnc(-c2cc(-c3ccc(F)cc3F)ccc2O)o1</smiles>

The interaction of 1-aryl-1,4-dihydro-6-methylpyridazine-4-on-3-carboxylic acid hydrazides with aryl isothiocyanates resulted in appropriate thiosemicarbazide derivatives $\mathbf{4 7}$ as key intermediates for the synthesis of pyridazinone substituted 1,3,4-oxadiazoles $\mathbf{4 8}$ (Zou et al., 2002).

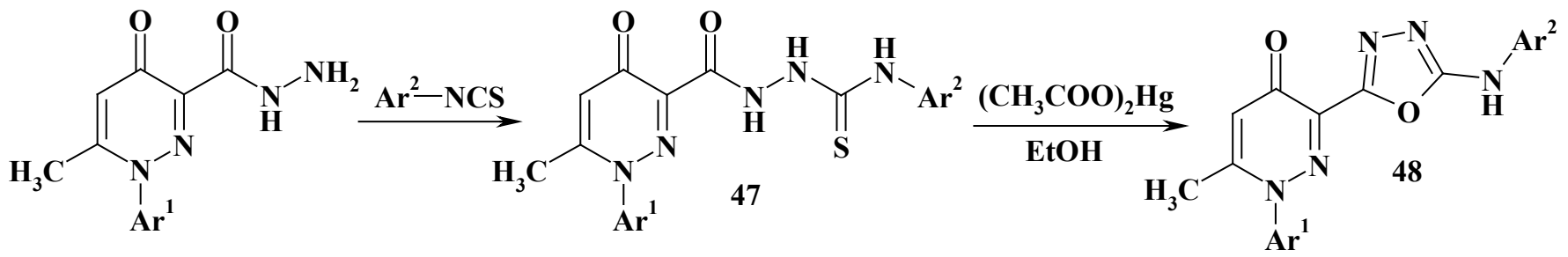

A similar approach for obtaining of 2,5-disubstituted 1,3,4-oxadiazoles was reported by Dolman et al. (2006). Thus, the target compounds $\mathbf{5 0}$ were prepared by the cyclodehydration of thiosemicarbazide precursors $\mathbf{4 9}$ mediated by tosyl chloride and organic base (pyridine) in tetrahydrofuran medium.

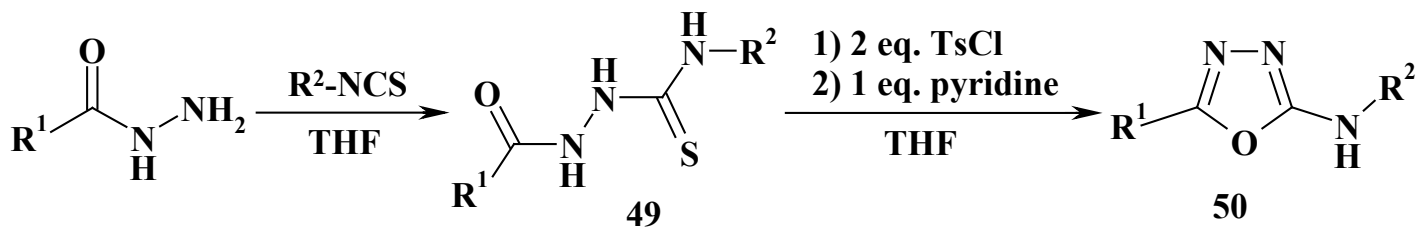

Based on the alkylation reaction of 2,4-thiazolidinedione potassium salt, generated in situ, and 1,3,4-oxadiazole substituted 2-chloroacetamides, a group of new bifunctional derivatives $\mathbf{5 1}$ were obtained. The synthesis of new 1,3,4-oxadiazole-, 4-thiazolidinone-, and indoline-based hybrids $\mathbf{5 2}$ was performed using standard Knoevenagel reaction procedure. Furthermore, the starting 1,3,4-oxadiazole- 
substituted 2-chloroacetamides were reacted with isatin derivatives at room temperature in dimethylformamide medium giving the corresponding 1-[2-(1,3,4-oxadiazol-2-yl)-2-oxoethyl]-1H-indole-2,3-diones 53 (Lelyukh et al., 2015).

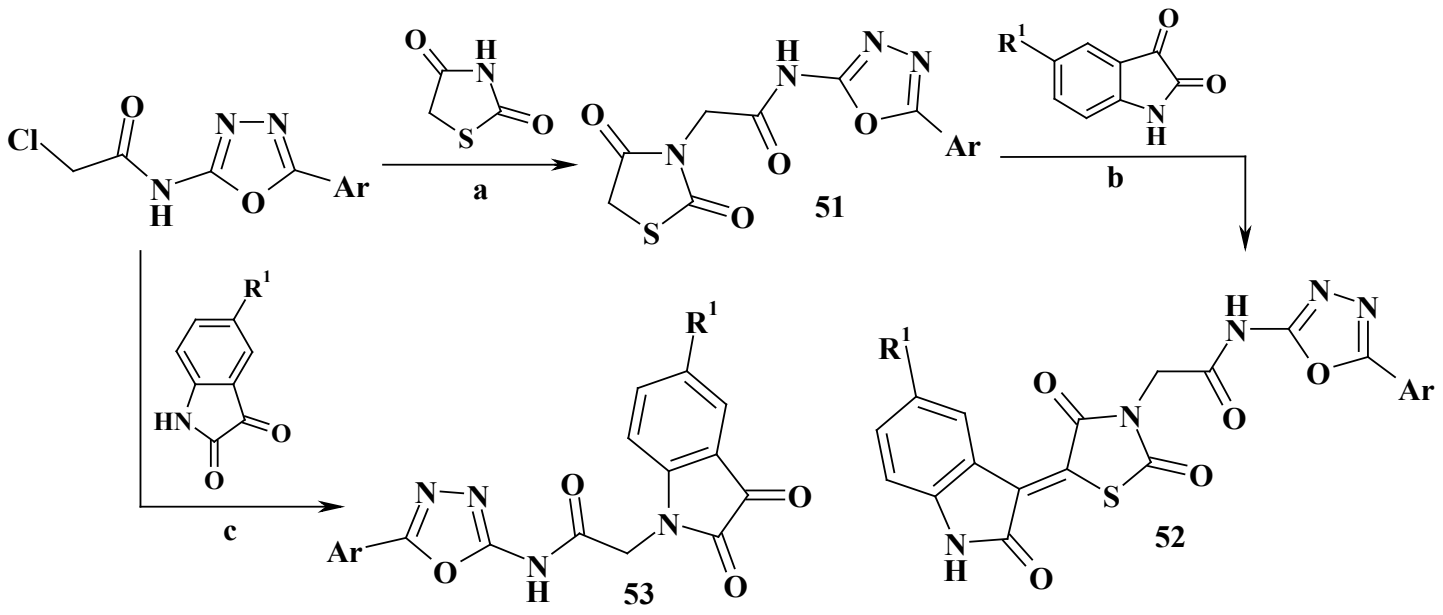

(a) KOH, KI, EtOH, reflux, 4-5h; (b) AcOH, AcONa, reflux, 3-4 h; (c) $\mathrm{K}_{2} \mathrm{CO}_{3}$, DMF, rt, $12 \mathrm{~h}$.

An effective one-pot synthesis of 1,3,4-oxadiazoles 54 from the acylhydrazines and isothiocyanates in dimethylformamide medium via polymer-supported (PS) reagents including PS-carbodiimide, P-propylamine, and PS-bemp had been reported by Coppo et al. (2004).

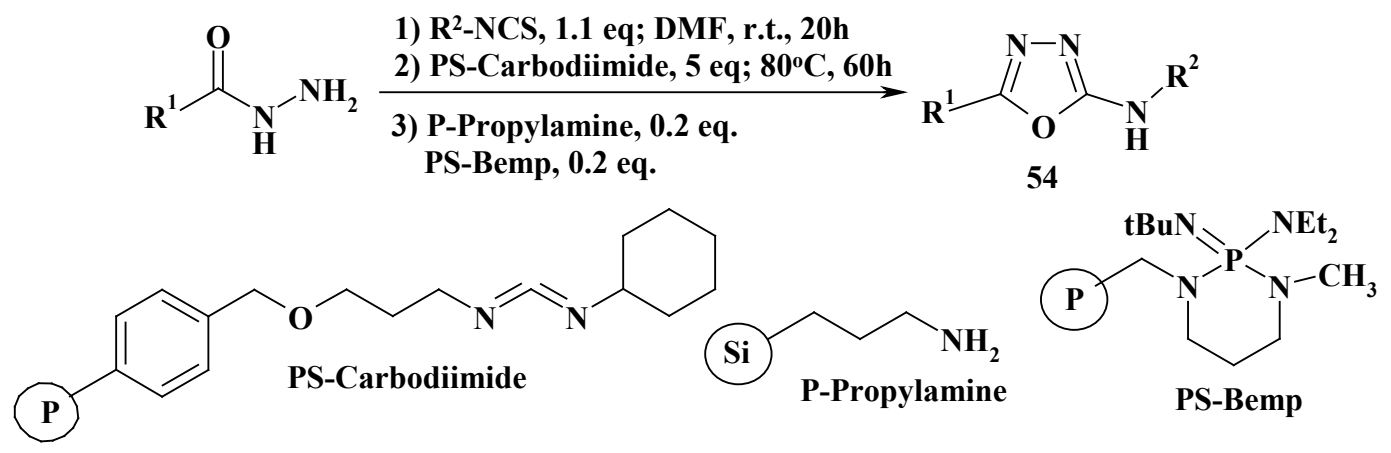

The synthesis of 2-arylamino-1,3,4-oxadiazole-5-carboxylic acid amides $\mathbf{5 5}$ as potential inhibitors of diacylglycerol acyl transferase-1 was carried out by McCoull et al. (2012). The library of target compounds was achieved through cyclocondensation of the corresponding acyl-hydrazines with various isothiocyanates using polymer-supported carbodiimide (PS-CDI) as a catalyst.

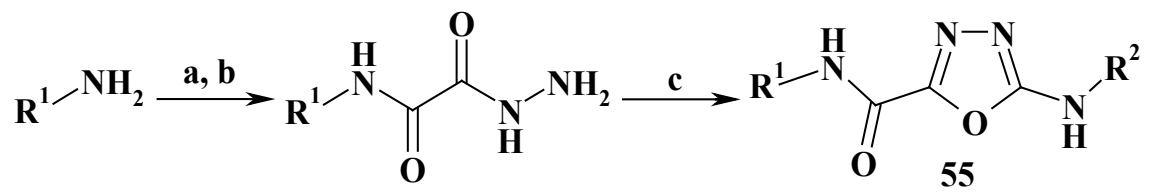

(a) MeOCOCOCl, pyridine, $\mathrm{CH}_{2} \mathrm{Cl}_{2}$; (b) $\mathrm{NH}_{2} \mathrm{NH}_{2}$, EtOH, reflux; (c) $\mathrm{R}^{2} \mathrm{NCS}$, PS-CDI.

The synthesis of 1,3,4-oxadiazoles $\mathbf{5 6}$ and $\mathbf{5 7}$ by visible-light-mediated decarboxylation-cyclization of hydrazides with isatin derivatives or phenylglyoxylic acid under mild conditions with the assistance of the photocatalyst eosin Y had been discovered. Using a series of control experiments, it was established that the visible light, eosin $\mathrm{Y}$, and base are essential conditions for the formation of the desired product in a good yield (Diao et al., 2018).

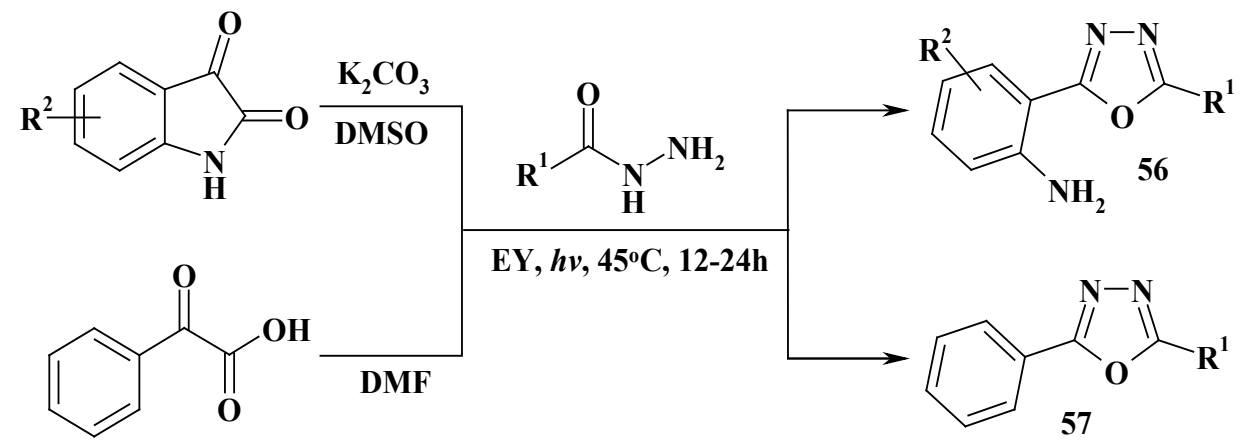


The interaction of 3,5-dinitrobenzyl isothiocyanate with sodium azide in toluene medium provided the corresponding $S$-substituted $1 H$-tetrazole-5-thiol 58, which recyclized under the action of acetic anhydride into 5-methyl-1,3,4-oxadiazole 59 (Karabanovich et al., 2016).

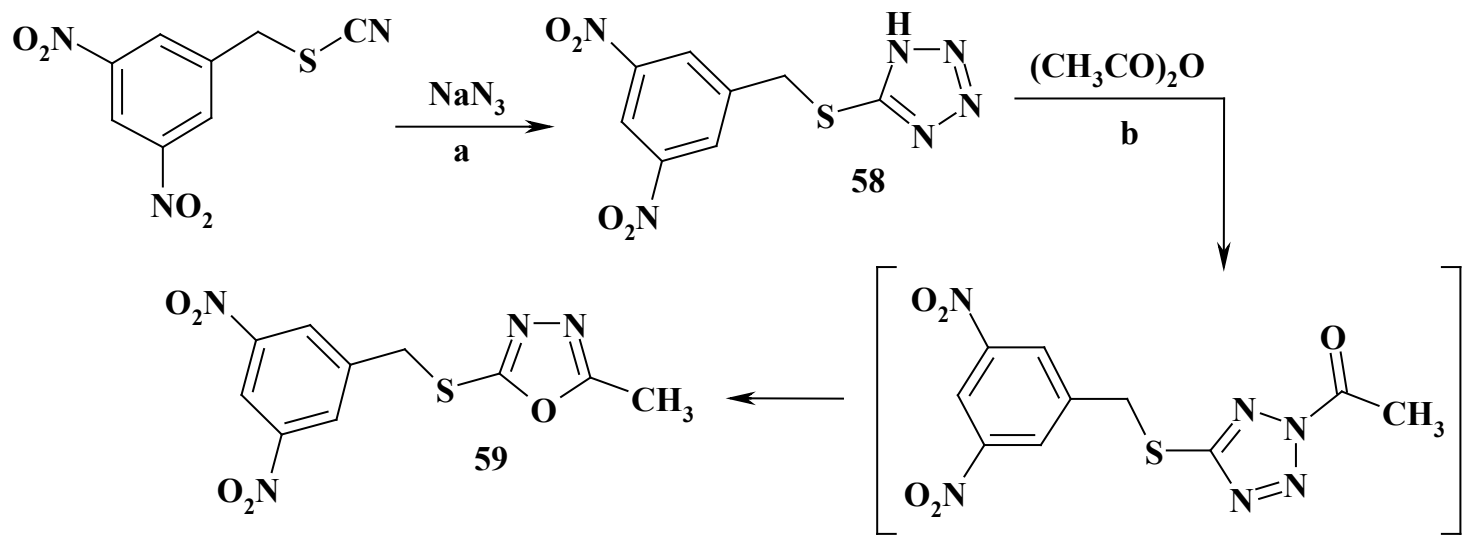

(a) $\mathrm{Et}_{3} \mathrm{~N} \cdot \mathrm{HCl}$, toluene, $1^{\circ} \mathrm{C}, 5 \mathrm{~h}, 68 \%$; (b) $\mathrm{MW}, 9^{\circ} \mathrm{C}, 10 \mathrm{~h}, 60 \%$.

A convenient one-pot method for the synthesis of 2-aryl-1,3,4-oxadiazoles 61 was performed via a two-component reaction between benzoic acid derivatives with ( $N$-isocyanimino)triphenylphosphorane at room temperature in dichloromethane medium (Souldozi and Ramazani, 2007). According to the authors, this interaction is accompanied by the formation of an intermediate adductiminophosphorane 60 - which then undergoes intramolecular $a z a$-Wittig reaction, yielding the title compounds 59 and triphenylphosphine:<smiles>[R]c1ccc(C(=O)O)cc1[R]</smiles>

60

A fundamentally new approach for the synthesis of 2,5-disubstituted 1,3,4-oxadiazoles $\mathbf{6 2}$ had been developed by Ramazani and Rezaei (2010). This procedure includes a one-pot four-component condensation reaction between ( $N$-isocyanimino)triphenylphosphorane, secondary amines, arylcarboxylic acids, and aromatic aldehydes and is followed by intramolecular $a z a$-Wittig ring closure without using any catalyst with stirring for 2 hours as shown as follows:

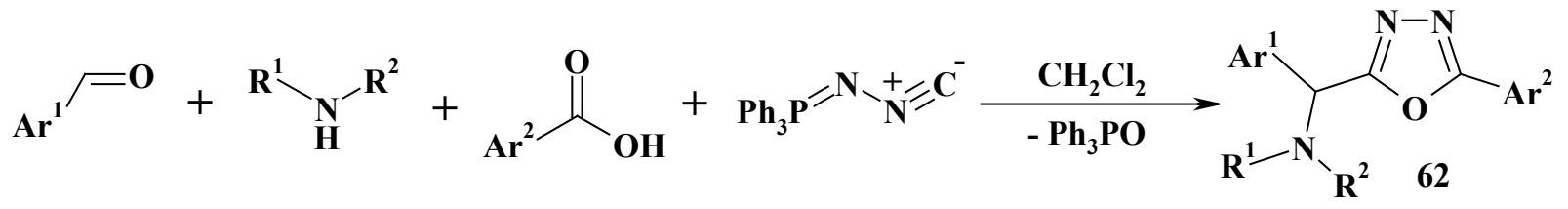

The synthesis of 2-[(1-benzylamino)cyclobutyl]-1,3,4-oxadiazoles $\mathbf{6 3}$ was performed according to the abovementioned multicomponent reaction condition using appropriate arylcarboxylic acids, cyclobutanone, benzylamine, and ( $N$-isocyanimino) triphenylphosphorane (Ramazani et al., 2011).

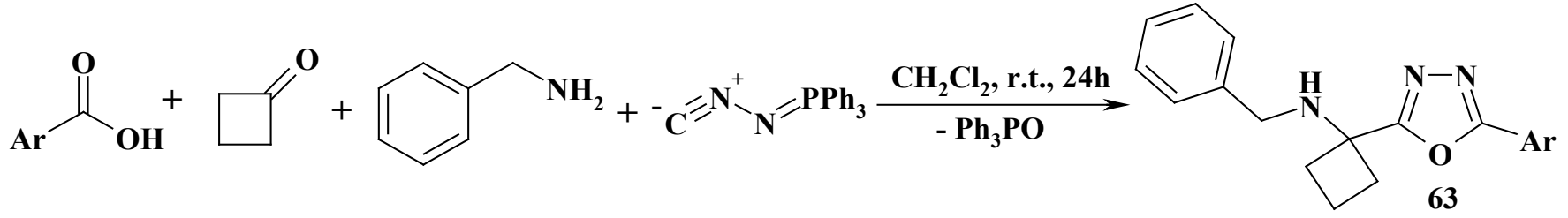


Biological activity of heterocyclic systems based on functionally substituted 1,3,4-oxadiazoles

The analysis of the anti-inflammatory activity of 1,3-diarylpyrazole substituted 1,3,4-oxadiazoles allowed establishing their group selectivity for cyclooxygenase (COX)-2 compared with COX-1. Among these compounds, $1 H$-pyrazolebased 5-phenyl-1,3,4-oxadiazole Ia and its 5-pyridyl substituted analog Ib (Figure 2) were identified with the $\mathrm{IC}_{50}$ values of 0.31 and $0.5 \mu \mathrm{M}$, respectively. The selectivity indices SI (relation $\mathrm{IC}_{50} \mathrm{COX}-1$ to $\mathrm{IC}_{50} \mathrm{COX}-2$ ) exceeded 200 and are comparable to that of standard cyclooxygenase-2 inhibitor celecoxib ( $\mathrm{IC}_{50}$ $=0.28 \mu \mathrm{M}$, SI > 357). The anti-inflammatory activity for both compounds was determined. As a result, the calculated values of effective concentration $\mathrm{ED}_{50}=74.3 \mathrm{mg} / \mathrm{kg}$ (Ia) and $72.6 \mathrm{мг} / \mathrm{\kappa г} \mathrm{(Ib)}$ in comparison with celecoxib $\left(\mathrm{ED}_{50}=81.7 \mathrm{mg} / \mathrm{kg}\right)$ and diclofenac $\left(\mathrm{ED}_{50}=110.4 \mathrm{mg} / \mathrm{kg}\right)$ show a significant pharmacological potential of pyrazole-oxadiazoles as selective COX-2 inhibitors (Bansal et al., 2014).

The anti-inflammatory activity investigation of 2-[(2-phenylamino)benzoyl]-5-aryl-1,3,4-oxadiazoles allowed identifying two effective compounds IIa and IIb (Figure 2) with an inhibition value of $68.36 \%$ and $63.26 \%$, respectively, at a dose of $100 \mathrm{mg} / \mathrm{kg}$ (Bala et al., 2013). The molecular docking studies for highly active compounds were performed to target COX-2. The scoring functional values of compounds IIa and IIb were much more than that of reference drug diclofenac but less than that of SC-S58 (selective COX-2 inhibitor).

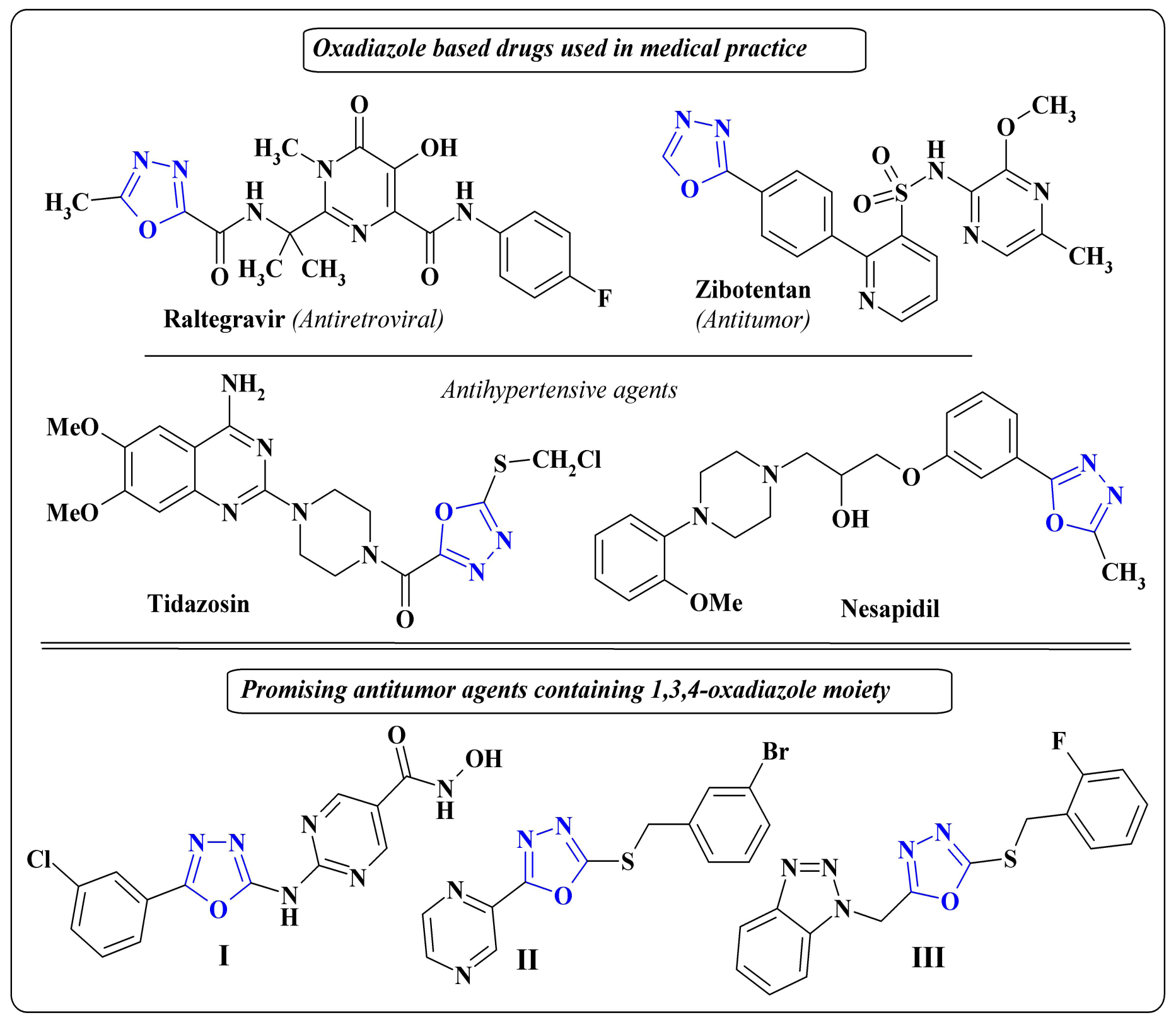

Figure 1. The pharmacological potential of 1,3,4-oxadiazole derivatives. 
Among 1,3,4-oxadiazole derivatives with $\beta$-(benzoyl) ethyl fragment, two compounds-namely, 1-(4-bromophenyl)3-[5-(4-chlorophenyl)-1,3,4-oxadiazole-2-yl]propan-1-on (IIIa) and 1-(4-bromophenyl)-3-[5-(3,4-dimethoxyphenyl)-1,3,4oxadiazole-2-yl] propan-1-on(IIIb) — were found(Figure 2), which suppressed by $59.5 \%$ and $61.9 \%$, respectively, the carrageenaninduced paw edema when administered orally at a dose of 100 $\mathrm{mg} / \mathrm{kg}$ (Husain et al., 2009). The calculated SI (severity index) values were equal to 0.75 (IIIa) and 0.83 (IIIb), which are lower than that of the starting compound, $\beta$-(4-bromobenzoyl)propionic acid $(\mathrm{SI}=1.17)$, and the reference drug indomethacin $(\mathrm{SI}=2.67)$, indicating a low toxicity of the evaluable compounds IIIa and IIIb.

The antibacterial and antifungal activities of 5-(4-methoxy-3-fluorophenyl)isoxazole derivatives bearing 1,3,4-oxadiazole moiety were appraised against Gram-positive and Gram-negative microorganisms (Staphylococcus aureus, Escherichia coli, and Pseudomonas aeruginosa) using ampicillin as the standard and several fungi strains including Aspergillus niger, Aspergillus clavatus, and Candida albicans using griseofulvin as the standard drug. As a result, a few compounds, namely, IVa-e (Figure 3), with promising antibacterial and antifungal action were identified (Shingare et al., 2018).

Based on the 3D QSAR analysis, the optimal structures were calculated, and the synthesis of 1,3,4-oxadiazoles as potential antibacterial agents was performed by Jha et al. (2010). For these compounds, the evaluation of antimicrobial activity against $E$. coli, Staphylococcus epidermidis, and $S$. aureus bacterial strains was carried out by disc diffusion method. According to the obtained results, two compounds, namely, 2-(2-acetoxyphenyl)1,3,4-oxadiazole-2-thiol $\mathbf{V}$ and 2-phenyl-5-(3-pyridyl)-1,3,4oxadiazole VI (Figure 3), exhibited the best activity with a range of growth inhibition zones of 24-26 mm (for comparison with standard drug ciprofloxacin, these parameters are 26, 30, and 29 $\mathrm{mm}$, respectively).

The group of indole- and pyridine-substituted 1,3,4-oxadiazoles was evaluated for their in vitro antitubercular activity at the concentrations of 30,10, and $3 \mathrm{lg} / \mathrm{ml}$ (Desai et al., 2016). The most active compounds VIIa-d (Figure 3) showed excellent MICs ranging from 0.94 to $5.17 \mu \mathrm{g} / \mathrm{ml}$ against Mycobacterium bovis bacillus Calmette-Guérin (BCG).

Among 2,5-disubstituted 1,3,4-oxadiazoles with 4-amino-2-methylpyrimidine fragment, compounds VIIIa-f (Figure 4) with a high in vivo activity level against tobacco mosaic virus had been identified. The $\mathrm{EC}_{50}$ value for the tested compound $(246.48 \mu \mathrm{g} / \mathrm{ml})$ was lower than that for standard antiviral drug ningnanmycin $\left(\mathrm{EC}_{50}=301.83 \mu \mathrm{g} / \mathrm{ml}\right)$ (Wu et al., 2015).

The group of 1,3,4-oxadiazole substituted 5-aryl-8hydroxy-1,6-naphthyridines was evaluated for their antiviral activity in a pseudotyped HIV cell-based assay (Johns et al., 2009a,

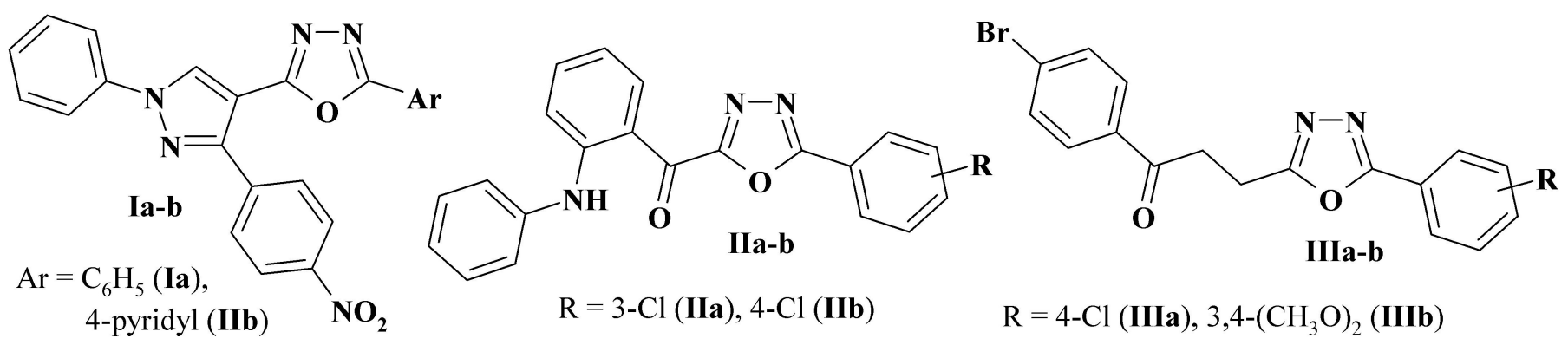

Figure 2. 1,3,4-Oxadiazole derivatives as potential anti-inflammatory agents.<smiles>[R]c1nnc(-c2cc(-c3ccc(OC)c(F)c3)on2)o1</smiles><smiles>CC(=O)Oc1ccccc1-c1nnc(S)o1</smiles>

$$
\begin{aligned}
\mathrm{R}= & 4-\mathrm{CH}_{3} \mathrm{O}-\mathrm{C}_{6} \mathrm{H}_{4}(\mathbf{I V a}), 2-\mathrm{CH}_{3} \mathrm{O}-\mathrm{C}_{6} \mathrm{H}_{4}(\mathbf{I V b}), \\
& 4-\mathrm{Cl}_{-}-\mathrm{C}_{6} \mathrm{H}_{4}(\mathbf{I V e}), 2,4-\mathrm{di}-\mathrm{Cl}^{-} \mathrm{C}_{6} \mathrm{H}_{3}(\mathbf{I V d}), \\
& \text { 3,4-di-Cl- }-\mathrm{C}_{6} \mathrm{H}_{3}(\mathbf{I V e})
\end{aligned}
$$
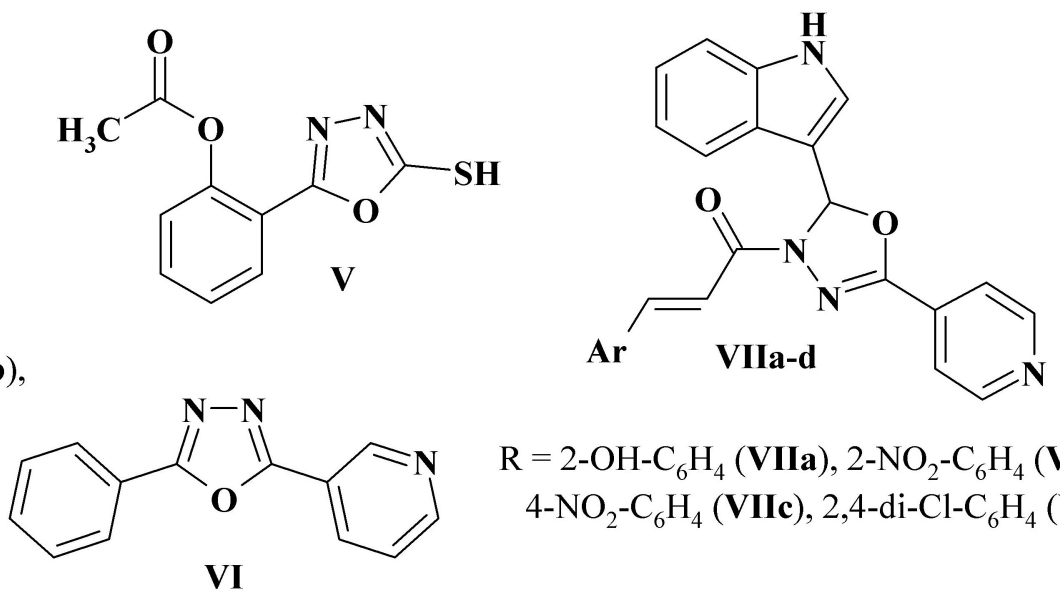

$\mathrm{R}=2-\mathrm{OH}-\mathrm{C}_{6} \mathrm{H}_{4}$ (VIIa), $2-\mathrm{NO}_{2}-\mathrm{C}_{6} \mathrm{H}_{4}$ (VIIb),

4- $\mathrm{NO}_{2}-\mathrm{C}_{6} \mathrm{H}_{4}$ (VIIc), 2,4-di-Cl- $\mathrm{C}_{6} \mathrm{H}_{4}$ (VIId)

Figure 3. Effective antimicrobial, antifungal, and antimycobacterial compounds based on 1,3,4-oxadiazole core. 


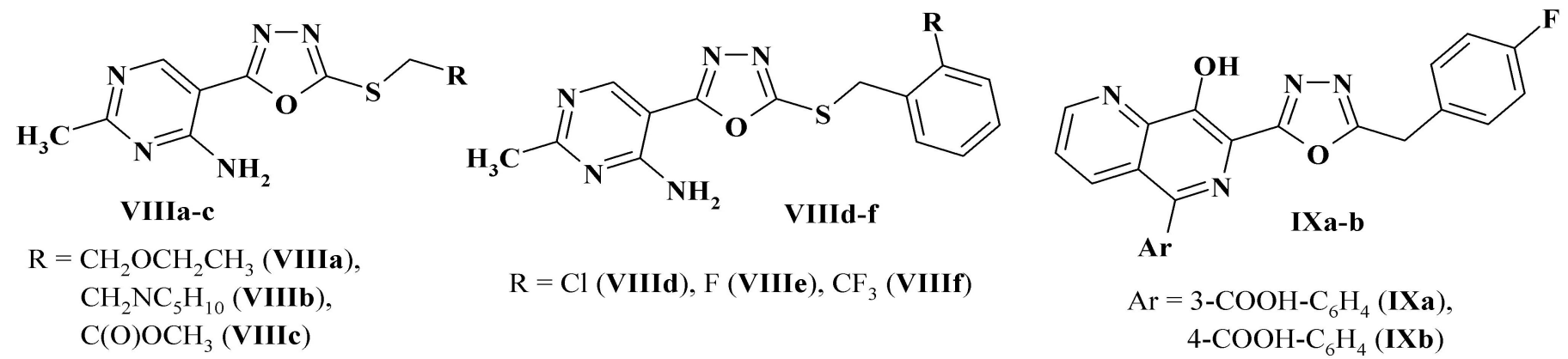

Figure 4. 1,3,4-Oxadiazole containing compounds with significant antiviral potential.<smiles>Oc1ccccc1-c1nn(CN[17F])c(=S)o1</smiles>

Xa-e<smiles>[Al]CSc1nnc(-c2ccc3c(c2)OCCO3)o1</smiles>

XIa-i

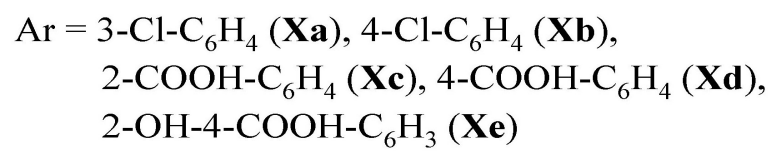

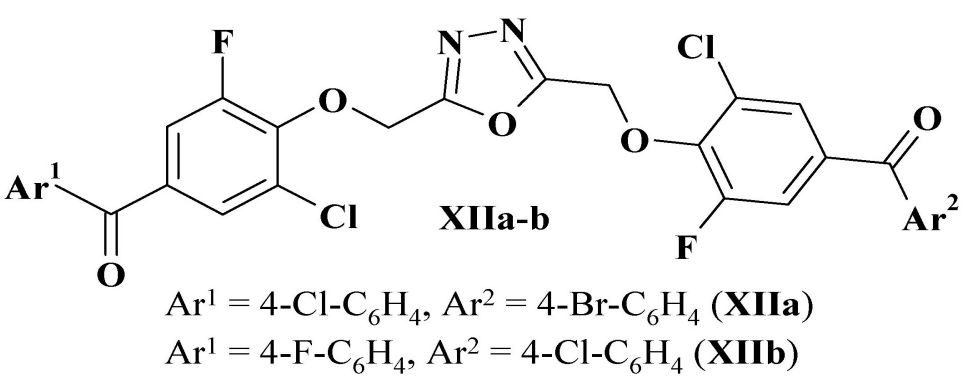

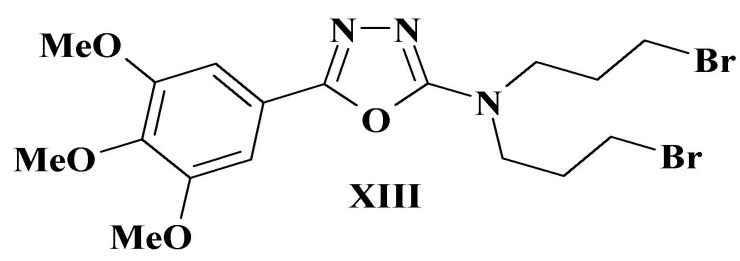

Figure 5. 1,3,4-Oxadiazole derivatives with a promising antitumor activity.

2009b). Among all compounds, the carboxylic acid analogs IXa and IXb (Figure 4) showed the most prominent HIV-1 integrase inhibitory activity with the $\mathrm{IC}_{50}$ values of $0.002 \mu \mathrm{M}$. Thus, it was observed that the presence of carboxygroup in the aryl fragment is most critical for the realization of HIV-1 inhibitory action.

The antiproliferative activity of 3-arylaminomethylene substituted 5-(2-hydroxyphenyl)-1,3,4-oxadiazole-2-thiones was studied for a full 60-cell lines panel according to the National Cancer Institute (NCI, USA) methodology. The screening result data indicated that two active compounds, namely, $\mathbf{X a}$ and $\mathbf{X b}$ (Figure 5), exhibited a moderate cytotoxic effect and explicit selectivity against certain human cancer cell lines with a growth inhibitory values $\left(\mathrm{MID} \mathrm{GI}_{50}\right.$ ) of -4.50 and -4.68 , respectively (Aboraia et al., 2006). It was concluded that the chlorosubstituted arylamino derivatives are the most active (Xa and $\mathbf{X b}$ ). Furthermore, compounds with carboxylic function, namely, $\mathbf{X c}\left(\mathrm{MID} \mathrm{GI}_{50}=-4.28\right), \mathbf{X d}\left(\mathrm{MID} \mathrm{GI}_{50}\right.$ $=-4.25)$, and $\mathbf{X e}\left(\mathrm{MID} \mathrm{GI}_{50}=-4.13\right)$, showed a high activity but lower than that of the chlorosubstituted analogs.
The antitumor activity investigation of 1,3,4-oxadiazoles bearing 1,4-benzodioxan moiety XIa-e (Figure 5) demonstrated their effectiveness against HEPG2, HELA, SW1116, and BGC823 cancer cell lines at micromolar concentrations ( range $\mathrm{IC}_{50}=7.21$ $19.98 \mu \mathrm{M}$ ) compared with the 5-fluorouracil (Zhang et al., 2011).

Among 2,5-di-(4-aroylaryloxymethyl)-1,3,4oxadiazoles, two highly active compounds XIIa-b (Figure 5) with high antiproliferative activities against human leukemic cell lines K562 and CEM were found (Gurupadaswamy et al., 2013). In particular, the mentioned compounds were more effective with a range of $\mathrm{IC}_{50}$ values of 10-16 $\mu \mathrm{M}$ than the comparison drug 5 -fluorouracil $\left(\mathrm{IC}_{50}(\mathrm{~K} 562)=28 \mu \mathrm{M}\right)$ and $\left.\left.\mathrm{IC}_{50}(\mathrm{CEM})=32 \mu \mathrm{M}\right)\right)$. Furthermore, it was established that the electron withdrawing halo groups at the para position in the benzophenone moieties are important for enhancing the inhibitory activity, whereas the electron releasing methyl group at the para position decreases the activity. 
The evaluation of the antimitotic activity using Onion Root Tip method displayed that 2-[N,N-di-(3-bromopropyl)amino]1,3,4-oxadiazole XIII (Figure 5) showed distinct antineoplastic effect with an $\mathrm{ID}_{50}$ value of $12.5 \mu \mathrm{M}$ when compared to its chemical precursor-appropriate 2-amino-1,3,4-oxadiazole $\left(\mathrm{ID}_{50}\right.$ $=34.5 \mu \mathrm{M})$. According to Lokanatha Rai et al. (2000), this effect may be due to the ability of compounds with $N, N$-di(bromopropyl) amino function to cyclization with the formation of a strained azetidinium ion, which further alkylates the $\mathrm{NH}, \mathrm{SH}$, or $\mathrm{OH}$ group of critical cell constituents, thereby blocking their function.

Besides, among oxadiazole derivatives, some hit compounds with antidiabetic (Taha et al., 2016), antioxidant (Patrao et al., 2013), and anticonvulsant (Rajak et al., 2013) activity were identified. The group of benzothiazole-substituted oxadiazoles was discovered as potential human protoporphyrinogen oxidase inhibitors (Jiang et al., 2010). An affinity of imidazo[1,2-a] pyrimidines with oxadiazole and related thiadiazole fragments to the benzodiazepine receptors was investigated (Tully et al., 1991). An immunosuppressive (Sun et al., 2011) and neuroprotective (Monte et al., 2013) activity evaluation for a group of 1,3,4-oxadiazoles with benzodioxan and benzodioxolane moieties was carried out.

\section{CONCLUSION}

In this review, we discuss the efforts to identify new promising compounds based on aryl/heteryl substituted noncondensed 1,3,4-oxadiazole derivatives, highlighting the main approaches for obtaining a chemical modification of the mentioned heterocycles and their pharmacological profile. 1,3,4-Oxadiazole heterocycle is a very interesting and important scaffold for modern organic and medicinal chemistry which demonstrated a wide range of biological activities including anticancer, antimicrobial, antitubercular, anti-inflammatory, and analgesic action. These ring systems are also featured in various approved drug structures such as Raltegravir (antiretroviral), Zibotentan (anticancer), and Tiodazosin and Nesapidil (antihypertensive). Thereby, the variety of the synthetic approaches of substituted 1,3,4-oxadiazoles and the widespread use of them in medicinal chemistry allow establishing this template as pharmacologically significant. All of the above can be considered as a background for further in-depth studies in the areas of chemistry and pharmacology of the mentioned heterocyclic systems with possible applications in medicine.

\section{CONFLICT OF INTEREST}

All authors confirmed that there is no conflict of interest.

\section{FUNDING}

None.

\section{REFERENCES}

Abbasi MA, Hassan M, Aziz-ur-Rehman, Siddiqui SZ, Raza $\mathrm{H}$, Shah SAA, Seo S-Y. Synthesis, in vitro and in silico studies of novel potent urease inhibitors: $N$-[4-(\{5-[(3-Un/substituted-anilino-3-oxopropyl)sulfanyl]-1,3,4-oxadiazol-2-yl\} methyl)-1,3-thiazol-2-yl]benzamides. Bioorg Med Chem, 2018; 26:3791-804.

Aboraia AS, Abdel-Rahman HM, Mahfouz NM, EL-Gendy MA. Novel 5-(2-hydroxyphenyl)-3-substituted-2,3-dihydro-1,3,4-oxadiazole-2thione derivatives: promising anticancer agents. Bioorg Med Chem, 2006; $14: 1236-46$.
Ahsan JA, Choupra A, Sharma RK, Jadav SS, Padmaja P, Hassan MZ, Al-Tamimi ABS, Geesi MH, Bakht MA. Rationale design, synthesis, cytotoxicity evaluation, and molecular docking studies of 1,3,4-oxadiazole analogues. Anticancer Agents Med Chem, 2018; 18:121-38.

Ahsan MJ, Samy JG, Khalilullah H, Nomani MdS, Saraswat P, Gaur R, Singh A. Molecular properties prediction and synthesis of novel 1,3,4-oxadiazole analogues as potent antimicrobial and antitubercular agents. Bioorg Med Chem Lett, 2011; 21:7246-50.

Akhter M, Husain A, Azad B, Ajmal M. Aroylpropionic acid based 2,5-disubstituted-1,3,4-oxadiazoles: synthesis and their antiinflammatory and analgesic activities. Eur J Med Chem, 2009; 44:2372-8.

Albratty M, El-Sharkawy KA, Alhazmi HA. Synthesis and evaluation of some new 1,3,4-oxadiazoles bearing thiophene, thiazole, coumarin, pyridine, and pyridazine derivatives as antiviral agents. Acta Pharm, 2019; 69:261-76.

Al-Omar MA. Synthesis and antimicrobial activity of new 5-(2-thienyl)-1,2,4-triazoles and 5-(2-thienyl)-1,3,4-oxadiazoles and related derivatives. Molecules, 2010; 15:502-14.

Bakht MA, Yar MS, Abdel-Hamid SG, Al Qasoumi SI, Samad A. Molecular properties prediction, synthesis and antimicrobial activity of some newer oxadiazole derivative. Eur J Med Chem, 2010; 45:5862-9.

Bala S, Kamboj S, Saini V, Prasad DN. Anti-inflammatory, analgesic evaluation and molecular docking studies of N-phenyl anthranilic acid-based 1,3,4-oxadiazole analogues. J Chem, 2013; 2013:6; doi: $10.1155 / 2013 / 412053$

Bansal S, Bala M, Suthar SK, Choudhary S, Bhattacharya S, Bhardway V, Singla S, Joseph A. Design and synthesis of novel 2-phenyl5-(1,3-diphenyl-1 $H$-pyrazol-4-yl)-1,3,4-oxadiazoles as selective COX-2 inhibitors with potent anti-inflammatory activity. Eur J Med Chem, 2014; 80:167-74.

Bondock S, Adel S, Etman HA, Badria FA. Synthesis and antitumor evaluation of some new 1,3,4-oxadiazole-based heterocycles. Eur J Med Chem, 2012; 48:192-9.

Boschelli DH, Connor DT, Bornemeier DA, Dyer RD, Kennedy JA, Kuipers PJ, Okonkwo GC, Schrier DJ, Wright CD. 1,3,4-Oxadiazole, 1,3,4-thiadiazole, and 1,2,4-triazole analogs of the fenamates: in vitro inhibition of cyclooxygenase and 5-lipoxygenase activities. J Med Chem, 1993; 36:1802-10.

Cahn P, Sued O. Raltegravir: a new antiretroviral class for salvage therapy. Lancet, 2007; 369:1235-6.

Chen H, Li Z, Han Y. Synthesis and fungicidal activity against rhizoctonia solani of 2-alkyl(alkylthio)-5-pyrazolyl-1,3,4-oxadiazoles (thiadiazoles). J Agric Food Chem, 2000; 48:5312-5.

Coppo FT, Evans KA, Graybill TL, Burton G. Efficient one-pot preparation of 5-substituted-2-amino-1,3,4-oxadiazole using resin-bound reagents. Tetrahedron Lett, 2004; 45:3257-60.

Desai NC, Somani H, Trivedi A, Bhatt K, Nawale L, Khedkar VM, Jha PC, Sarkar D. Synthesis, biological evaluation and molecular docking study of some novel indole and pyridine based 1,3,4-oxadiazole derivatives as potential antitubercular agents. Bioorg Med Chem Lett, 2016; 26:1776-83.

Desai NC, Trivedi A, Somani H, Jadeja KA, Vaja D, Nawale L, Khedkar VM, Sarkar D. Synthesis, biological evaluation, and molecular docking study of pyridine clubbed 1,3,4-oxadiazoles as potential antituberculars. Synth Commun, 2018; 48(5):524-40.

Dhumal ST, Deshmukh AR, Bhosale MR, Khedkar VM, Nawale LU, Sarkar D, Mane RA. Synthesis and antitubercular activity of new 1,3,4-oxadiazoles bearing pyridyl and thiazolyl scaffolds. Bioorg Med Chem Lett, 2016; 26:3646-51.

Diao P, Ge Y, Zhang W, Xu C, Zhang N, Guo C. Synthesis of 2,5-disubstituted 1,3,4-oxadiazoles by visible-light-mediated decarboxylation-cyclization of hydrazides and diketones. Tetrahedron Lett, 2018; 59:767-70.

Dolman SJ, Gosselin F, O'Shea PD, Davies IW. Superior reactivity of thiosemicarbazides in the synthesis of 2-amino-1,3,4oxadiazoles. J Org Chem, 2006; 71:9548-51. 
Feng CT, Wang LD, Yan YG, Liu J, Li SH. Synthesis and antitumor evaluation of some 1,3,4-oxadiazole-2 $(3 H)$-thione and 1,2,4-triazole-5(1H)-thione derivatives. Med Chem Res, 2012; 21:315-20.

Gan X, Hu D, Li P, Wu J, Chen X, Xue W, Song B. Design, synthesis, antiviral activity and 3D-QSAR study of novel 1,4-pentadien3-one derivatives containing the 1,3,4-oxadiazole moiety. Pest Manag Sci, 2016; 72(3):534-43.

Grinsztejn B, Nguyen B-Y, Katlama C, Gatell JM, Lazzarin A, Vittecoq D, Gonzalez CJ, Chen J, Harvey CM, Isaacs RD. Safety and efficacy of the HIV-1 integrase inhibitor Raltegravir (MK-0518) in treatment-experienced patients with multidrug-resistant virus: a phase II randomised controlled trial. Lancet, 2007; 369:1261-9.

Guimarães CRW, Boger DL, Jorgensen WL. Elucidation of fatty acid amide hydrolase inhibition by potent $\alpha$-ketoheterocycle derivatives from Monte Carlo simulations. J Am Chem Soc, 2005; 127:17377-84.

Gurupadaswamy HD, Girish V, Kavitha CV, Raghavan SC, Kharum SA. Synthesis and evaluation of 2,5-di(4-aryloylaryloxymethyl)1,3,4-oxadiazole as anticancer agents. Eur J Med Chem, 2013; 63:536-43.

Hashem AI, Youssef ASA, Kandeel KA, Abou-Elmagd WSI. Conversion of some $2(3 H)$-furanones bearing a pyrazolyl group into other heterocyclic systems with a study of their antiviral activity. Eur J Med Chem, 2007; 42:934-9.

Husain A, Ajmal M. Synthesis of novel 1,3,4-oxadiazole derivatives and their biological properties. Acta Pharm, 2009; 59:223-33.

Jakubkiene V, Burbuliene MM, Mekuskiene G, Udrenaite E, Gaidelis P, Vainilavicius P. Synthesis and anti-inflammatory activity of 5-(6-methyl-2-substituted 4-pyrimidinyloxymethyl)-1,3,4-oxadiazole2-thiones and their 3-morpholinomethyl derivatives. Il Farmaco, 2003; $58: 323-8$.

Jha KK, Samad A, Kumar Y, Shaharyar M, Lal Khosa R, Jain J, Kumar V, Singh P. Design, synthesis and biological evaluation of 1,3,4-oxadiazole derivatives. Eur J Med Chem, 2010; 45:4963-7.

Jiang L-L, Tan Y, Zhu X-L, Wang Z-F, Zuo Y, Chen Q, Xi Z, Yang G-F. Design, synthesis and 3D-QSAR analysis of novel 1,3,4-oxadiazol$2(3 H)$ ones as protoporphyrinogen oxidase inhibitors. J Agric Food Chem, 2010; 58:2643-51.

Johns BA, Weatherhead JG, Allen SH, Thompson JB, Garvey EP, Foster SA, Jeffrey JL, Miller WH. The use of oxadiazole and triazole substituted naphthyridines as HIV-1 integrase inhibitors. Part 1: establishing the pharmacophore. Bioorg Med Chem Lett, 2009a; 19:1802-6.

Johns BA, Weatherhead JG, Allen SH, Thompson JB, Garvey EP, Foster SA, Jeffrey JL, Miller WH. 1,3,4-Oxadiazole substituted naphthyridines as HIV-1 integrase inhibitors. Part 2: SAR of the $\mathrm{C} 5$ position. Bioorg Med Chem Lett, 2009b; 19:1807-10.

Kamal A, Dastagiri D, Ramaiah MJ, Bharathi EV, Reddy JS, Balakishan G, Sarma P, Pushpavalli SNCVL, Pal-Bhadra M, Juvekar A, Sen S, Zingde S. Synthesis, anticancer activity and mitochondrial mediated apoptosis inducing ability of 2,5-diaryloxadiazole-pyrrolobenzodiazepine conjugates. Bioorg Med Chem, 2010; 18:6666-77.

Karabanovich G, Zemanova J, Smutny T, Szekely R, Sarkan M, Centarova I, Vocat A, Pavkova I, Conka P, Nemecek J, Stolarikova J, Vejsova M, Vavrova K, Klimesova V, Hrabalek A, Pavek P, Cole ST, Mikusova K, Roh J. Development of 3,5-dinitrobenzylsulfanyl-1,3,4-oxadiazoles and thiadiazoles as selective antitubercular agents active against replicating and nonreplicating Mycobacterium tuberculosis. J Med Chem, 2016; 59:2362-80.

Kashtoh H, Hussain S, Khan A, Saad SM, Khan JAJ, Khan KM, Perveen S, Choudhary MI. Oxadiazoles and thiadiazoles: novel $\alpha$-glucosidase inhibitors. Bioorg Med Chem, 2014; 22:5454-65.

Khan KM, Fatima N, Rasheed M, Jalil S, Ambreen N, Perveen S, Choudhary MI. 1,3,4-Oxadiazole-2(3H)-thione and its analogues: a new class of non-competitive nucleotide pyrophosphatases/ phosphodiesterases 1 inhibitors. Bioorg Med Chem, 2009; 17:7816-22.

Khan MTH, Choudhary MI, Khan KM, Rani M, Atta-ur-Rahman. Structure-activity relationships of tyrosinase inhibitory combinatorial library of 2,5-disubstituted-1,3,4-oxadiazole analogues. Bioorg Med Chem, 2005; 13:3385-95.
Koparir M, Cetin A, Cansiz A. 5-Furan-2-yl-1,3,4-oxadiazole2-thiol, 5-furan-2-yl-4H-1,2,4-triazole-3-thiol and their thiol-thione tautomerism. Molecules, 2005; 10:475-80.

Kotaiah Y, Harikrishna N, Nagaraju K, Rao CV. Synthesis and antioxidant activity of 1,3,4-oxadiazole tagged thieno[2,3- $d]$ pyrimidine derivatives. Eur J Med Chem, 2012; 58:340-5.

Küçükgüzel ŞG, Küçükgüzel I, Tatar E, Rollas S, Şahin F, Güllüce M, De Clercq E, Kabasakal L. Synthesis of some novel heterocyclic compounds derived from diflunisal hydrazide as potential anti-infective and anti-inflammatory agents. Eur J Med Chem, 2007; 42:893-901.

Lelyukh M, Havrylyuk D, Lesyk R. Synthesis and anticancer activity of isatin, oxadiazole and 4-thiazolidinone based conjugates. Chem Chem Technol, 2015; 9(1):29-36.

Li Y, Liu J, Zhang H, Yang X, Liu Z. Stereoselective synthesis and fungicidal activities of $(E)$ - $\alpha$-(methoxyimino)-benzeneacetate derivatives containing 1,3,4-oxadiazole ring. Bioorg Med Chem Lett, 2006 16:2278-82.

Lokanatha Rai KM, Linganna N. Synthesis and evaluation of antimitotic activity of alkylated 2-amino-1,3,4-oxadiazole derivatives. Il Farmaco, 2000; 55:389-92.

Madhavilatha B, Bhattacharjee D, Sabitha G, Reddy BVS, Yadav JS, Jain N, Reddy BJM. Synthesis and in vitro anticancer activity of novel 1,3,4-oxadiazole-linked 1,2,3-triazole/isoxazole hybrids. J Heterocycl Chem, 2018; 55(4):863-70.

Madhu Sekhar M, Nagarjuna U, Padmavathi V, Padmaja A, Vasudeva Reddy N, Vijaya T. Synthesis and antimicrobial activity of pyrimidinyl 1,3,4-oxadiazoles, 1,3,4-thiadiazoles and 1,2,4-triazoles. Eur J Med Chem, 2018; 145:1-10.

McCoull W, Addie MS, Birch AM, Birtles S, Buckett LK, Butlin RJ, Bowker SS, Boyd S, Chapman S, Davies RDM, Donald CS, Green CP, Jenner C, Kemmit PD, Leach AG, Moody GC, Gutierrez PM, Newcombe NJ, Nowak T, Packer MJ, Plowright AT, Revill J, Schofield P, Sheldon C, Stokes S, Turnbull AV, Wang SJY, Whalley DP, Wood JM. Identification, optimisation and in vivo evaluation of oxadiazole DGAT1 inhibitors for the treatment of obesity and diabetes. Bioorg Med Chem Lett, 2012; 22:3873-8.

Monte FL, Kramer T, Gu J, Brodrecht M, Pilakowski J, Fuertes A, Dominguez JM, Plotkin B, Eldar-Finkelman H, Schmidt B. Structurebased optimization of oxadiazole-based GSK-3 inhibitors. Eur J Med Chem, 2013; 61:26-40

Naveena CS, Boja P, Kumari NS. Synthesis, characterization and antimicrobial activity of some disubstituted 1,3,4-oxadiazoles carrying 2-(aryloxymethyl)phenyl moiety. Eur J Med Chem, 2010; 45:4708-19.

Nimbalkar UD, Tupe SG, Vazques JAS, Khan FAK, Sangshetty JN, Nikalje APG. Ultrasound- and molecular sieves-assisted synthesis, molecular docking and antifungal evaluation of 5-(4-(benzyloxy)substituted phenyl)-3-((phenylamino)methyl)-1,3,4-oxadiazole-2(3H)thiones. Molecules, 2016; 21(5), 484.

Padmavathi V, Reddy GD, Reddy SN, Malesh K. Synthesis and biological activity of 2-(bis((1,3,4-oxadiazolyl/1,3,4-thiadiazolyl) methylthio)methylene)malononitriles. Eur J Med Chem, 2011; 46:1367-73.

Palmer JT, Hirschbein BL, Cheung H, McCarter J, Janc JW, Yu ZW, Wesolowski G. Keto-1,3,4-oxadiazoles as cathepsin K inhibitors. Bioorg Med Chem Lett, 2006; 16:2909-14.

Patrao P, Khader AMA, Kalluraya B, Vinayachandra. Synthesis of new 5-naphthyl substituted 1,3,4-oxadiazole derivatives and their antioxidant activity. Der Pharm Chem, 2013; 5(2):24-32.

Puthiyapurayil P, Poojary B, Chikkanna C, Buridipad SK. Design, synthesis and biological evaluation of a novel series of 1,3,4-oxadiazole bearing $N$-methyl-4-(trifluoromethyl)phenyl pyrazole moiety as cytotoxic agents. Eur J Med Chem, 2012; 53:203-10.

Rajak H, Agarawal A, Parmar P, Thakur BS, Veerasamy R, Sharma PC, Kharya MD. 2,5-Disubstituted-1,3,4-oxadiazoles/thiadiazoles as surface recognition moiety: design and synthesis of novel hydroxamic acid based histone deacetylase inhibitors. Bioorg Med Chem Lett, 2011; 21:5735-8. 
Rajak H, Kharya MD, Mishra P. Synthesis and local anesthetic activity of some novel $\mathrm{N}$-[5-(4-substituted)phenyl-1,3,4-oxadiazol-2-yl]-2(substituted)-acetamides. Arch Pharm, 2008; 341:247-61.

Rajak H, Thakur BS, Singh A, Raghuvanshi K, Sah AK, Veerasamy R, Sharma PC, Pawar RS, Kharya MD. Novel limonene and citral based 2,5-disubstituted-1,3,4-oxadiazoles: a natural product coupled approach to semicarbazones for antiepileptic activity. Bioorg Med Chem Lett, 2013; 23:864-8.

Ramazani A, Rezaei A. Novel one-pot, four-component condensation reaction: an efficient approach for the synthesis of 2,5-disubstituted 1,3,4-oxadiazole derivatives by Ugi-4CR/aza-Wittig sequence. Org Lett, 2010; 12:2852-5.

Ramazani A, Shajari N, Mahyari A, Ahmadi Y. A novel fourcomponent reaction for the synthesis of disubstituted 1,3,4-oxadiazole derivatives. Mol Divers, 2011; 15:521-7.

Rasheed H, Afridi R, Khan AU, Ullah MZ, Khalid S, Atiq A, Kashif H, Ahmed MN, Kim YS, Khan S. Anti-inflammatory, antirheumatic and analgesic activities of 2-(5-mercapto-1,3,4-oxadiazol-2-yl)$N$-propylbenzenesulphonamide (MOPBS). Inflammopharmacology, 2018; 26(4):1037-49.

Rashid M, Husain A, Mishra R. Synthesis of benzimidazole bearing oxadiazole nucleus as anticancer agents. Eur J Med Chem, 2012; 54:855-66.

Rohand T, Ramli Y, Baruah M, Budka J, Das AM. Synthesis, structure elucidation and antimicrobial properties of new bis-1,3,4 oxadiazole derivatives. Pharm Chem J, 2019; 53(2):150-4.

Shingare RM, Patil YS, Sangshetty JN, Patil RB, Rajani DP, Madje BR. Synthesis, biological evaluation and docking study of some novel isoxazole clubbed 1,3,4-oxadiazoles derivatives. Med Chem Res, 2018; 27(4):1283-91.

Souldozi A, Ramazani A. The reaction of ( $N$-isocyanimino) triphenylphosphorane with benzoic acid derivatives: a novel synthesis of 2-aryl-1,3,4-oxadiazole derivatives. Tetrahedron Lett, 2007; 48:1549-51.

Sun J, Cao N, Zhang X-M, Yang Y-S, Zhang Y-B, Wang X-M, Zhu H-L. Oxadiazole derivatives containing 1,4-benzodioxan as potential immunosuppressive agents against RAW246.7 cells. Bioorg Med Chem, 2011; 19:4895-902.

Taha M, Ismail NH, Jamil W, Imran S, Rahim F, Kashif SM, Zulkefeli M. Synthesis of 2-(2-methoxyphenyl)-5-phenyl-1,3,4-oxadiazole derivatives and evaluation of their antiglycation potential. Med Chem Res, $2016 ; 25: 225-34$.

Tantray MA, Khan I, Hamid H, Alam MS, Dhulap A, Kalam A. Synthesis of benzimidazole-linked-1,3,4-oxadiazole carboxamides as GSK-3 $\beta$ inhibitors with in vivo antidepressant activity. Bioorg Chem, 2018; 77:393-401.
Tully WR, Gardner CR, Gillespie RJ, Westwood R. 2-(Oxadiazolyl)- and 2-(thiazolyl)imidazo[1,2-a]pyrimidines as agonists and inverse agonists at benzodiazepine receptors. J Med Chem, 1991; 34:2060-7.

Wu W, Chen Q, Tai A, Jiang G, Ouyang G. Synthesis and antiviral activity of 2-substituted methylthio-5-(4-amino-2-methylpyrimidin-5-yl)1,3,4-oxadiazole derivatives. Bioorg Med Chem Lett, 2015; 25:2243-6.

Zarghi A, Tabatabai SA, Faizi M, Ahadian A, Navabi P, Zanganeh V, Shafiee A. Synthesis and anticonvulsant activity of new 2-substituted5-(2-benzyloxyphenyl)-1,3,4-oxadiazoles. Bioorg Med Chem Lett, 2005; $15: 1863-5$.

Zhang S, Luo Y, He L-Q, Liu Z-J, Jiang A-Q, Yang Y-H, Zhu H-L. Synthesis, biological evaluation, and molecular docking studies of novel 1,3,4-oxadiazole derivatives possesing benzotriazole moiety as FAK inhibitors with anticancer activity. Bioorg Med Chem, 2013; 21:3723-9.

Zhang X-M, Qiu M, Sun J, Zhang Y-B, Yang Y-S, Wang X-L, Tang J-F, Zhu H-L. Synthesis, biological evaluation, and molecular docking studies of 1,3,4-oxadiazole derivatives possessing 1,4-benzodioxan moiety as potential anticancer agents. Bioorg Med Chem, 2011; 19:6518-24.

Zhang Y-B, Wang X-L, Liu W, Yang Y-S, Tang J-F, Zhu H-L. Design, synthesis and biological evaluation of heterocyclic azoles derivatives containing pyrazine moiety as potential telomerase inhibitors. Bioorg Med Chem, 2012a; 20:6356-65.

Zhang Z-M, Zhang X-W, Zhao Z-Z, Yan R, Xu R, Gong H-B, Zhu H-L. Synthesis, biological evaluation and molecular docking studies of 1,3,4-oxadiazole derivatives as potent immunosuppressive agents. Bioorg Med Chem, 2012b; 20:3359-67.

Zou X-J, Lai L-H, Jin G-Y, Zhang Z-X. Synthesis, fungicidal activity, and 3D-QSAR of pyridazinone-substituted 1,3,4-oxadiazoles and 1,3,4-thiadiazoles. J Agric Food Chem, 2002; 50:3757-60.

How to cite this article:

Lelyukh M, Martynets M, Kalytovska M, Harkov S, Drapak I, Chaban T, Chaban I, Matiychuk V. Approaches for synthesis and chemical modification of non-condensed heterocyclic systems based on 1,3,4-oxadiazole ring and their biological activity: a review. J Appl Pharm Sci, 2020; 10(10):151-165. 